\title{
Wave Energy Resource Assessment for Exploitation-A Review
}

\author{
Nicolas Guillou ${ }^{1, *(1)}$, George Lavidas ${ }^{2}$ and Georges Chapalain ${ }^{1}$ \\ 1 Laboratoire de Génie Côtier et Environnement (LGCE), Direction Eau Mer et Fleuves, \\ Département Environnement et Risques, Cerema, 155 rue Pierre Bouguer Technopôle Brest-Iroise, BP 5, \\ 29280 Plouzané, France; georges.chapalain@cerema.fr \\ 2 Faculty of Civil Engineering and Geosciences, Stevinweg 1, 2628 CN Delft, The Netherlands; \\ g.lavidas@tudelft.nl or glavidas@gmail.com \\ * Correspondence: nicolas.guillou@cerema.fr; Tel.: +33-29805-6739
}

Received:17 August 2020 2020; Accepted: 9 September 2020; Published: 11 September 2020

check for updates

\begin{abstract}
Over recent decades, the exploitation of wave energy resources has sparked a wide range of technologies dedicated to capturing the available power with maximum efficiency, reduced costs, and minimum environmental impacts. These different objectives are fundamental to guarantee the development of the marine wave energy sector, but require also refined assessments of available resource and expected generated power to optimize devices designs and locations. We reviewed here the most recent resource characterizations starting from (i) investigations based on available observations (in situ and satellite) and hindcast databases to (ii) refined numerical simulations specifically dedicated to wave power assessments. After an overall description of formulations and energy metrics adopted in resource characterization, we exhibited the benefits, limitations and potential of the different methods discussing results obtained in the most energetic locations around the world. Particular attention was dedicated to uncertainties in the assessment of the available and expected powers associated with wave-climate temporal variability, physical processes (such as wave-current interactions), model implementation and energy extraction. This up-to-date review provided original methods complementing the standard technical specifications liable to feed advanced wave energy resource assessment.
\end{abstract}

Keywords: inter-annual and inter-seasonal variability; wave-current interactions; coastal shelf seas; wave energy metrics; numerical spectral wave models; wave energy converters

\section{Introduction}

The exploitation of ocean renewable energy is an emerging alternative to the consumption of polluting and declining fossil fuels resources, contributing at the same time to the energy independence of marine countries. Among the different forms of ocean renewable energy, the wave resource is one of the most abundant with (i) a high power density in coastal waters (and thus a great number of potential sites for energy exploitation [1]), but also (ii) future expected increases due to climate change (with potential changes in the spatio-temporal variability of available wave power [2]). Its exploitation can furthermore be valuable for marine regions with high energy costs such as island territories [3]. Wave energy can finally complement other forms of renewable resources (including solar, wind and tidal stream energies) leading to lower energy infrastructure costs and reduced energy storage requirements.

However, despite a wide range of technical solutions tested and deployed in real sea conditions to convert wave energy into electricity [4], the resource exploitation still shows high economic uncertainty. Indeed, wave energy converters (WEC) may potentially have a reduced lifespan with significant 
construction and maintenance costs as devices must withstand harsh environmental conditions, including severe storms, but also saltwater corrosive effects and biofouling [5]. WEC performances remain furthermore lower than other types of marine energy converters, and these performances are impacted by the high annual and seasonal variability of the wave resource [6]. A device may thus show yearly averaged high efficiency whereas it is designed for winter conditions, only. The energy production may also vary from one year to another as a consequence of resource inter-annual variability. Thus, further problems may arise for incorporating the unsteady generated power into local electrical grids, primary adapted to a consistent power supply [7].

In recent decades, these different issues have led to the failure of numerous wave power projects including, among the most famous, the Aguçadoura Wave Farm in Portugal (Europe), the first wave farm in the world which integrated three Pelamis devices [8]. However, the wave energy industry has still a role to play in the exploitation of ocean energy as exhibited by recent innovative projects that may pave the way for the economic feasibility of wave energy exploitation. This is, for instance, the case of the Eco Wave Power project which consists of attaching an array of small buoys, dedicated to wave energy conversion, to existing coastal structures, such as dikes [9]. The idea brings many benefits, facilitating maintenance while reducing transmission lines, interactions with coastal activities and effects on marine life. Pilot projects were installed in Israel and Gibraltar, and connected to the grid. Another example is the Power Buoy device, designed by Ocean Power Technology, which consists of exploiting the movement of a surface buoy [10]. The innovation lies in the advanced technology that enables monitoring of and adaptation to environmental conditions; thus optimizing wave energy exploitation while increasing the lifespan of devices. Pilot projects exist in the United-Kingdom and the United-States. Following this fresh impetus, the next few years may therefore give birth to next-generation projects liable to promote the growth of a reliable wave energy exploitation.

However, such expected evolution requires securing of the key steps of a wave energy project, guaranteeing the capital investment and the economical return. Refined resource assessments are, in particular, fundamental to (i) identify the most promising locations for energy exploitation and (ii) optimize WEC design and construction costs to environmental conditions and available power [5]. For these reasons, a series of specifications and recommendations were established to conduct appropriate and accurate wave energy resource assessments [11-14]. An evolution of standards by Ingram et al. [14] is the Technical Specification set up by the Marine Renewable Energy Technical Committee (TC114) of the International Electrotechnical Commission (IEC) [15]. Following this specification, a wave energy resource assessment should cover a minimum period of ten years with data available at a minimum time step of three hours. The spatial resolution of numerical applications should also vary with respect to the stage of the wave project: reconnaissance, feasibility or design (Table 1).

Table 1. IEC Technical Specification categories of resource assessments [15].

\begin{tabular}{ccccc}
\hline Categories & $\begin{array}{c}\text { Typical } \\
\text { Domains }\end{array}$ & $\begin{array}{c}\text { Spatial } \\
\text { Extends }\end{array}$ & $\begin{array}{c}\text { Min. Spatial } \\
\text { Resolutions }\end{array}$ & $\begin{array}{c}\text { Min. Temporal } \\
\text { Resolutions }\end{array}$ \\
\hline Reconnaissance & Oceanic regions & $\geq 300 \mathrm{~km}$ & $5 \mathrm{~km}$ & $3 \mathrm{~h}$ \\
Feasibility & Nearshore/shallow waters & $20-500 \mathrm{~km}$ & $500 \mathrm{~m}$ & $3 \mathrm{~h}$ \\
Design & Wave farm & $\leq 25 \mathrm{~km}$ & $50 \mathrm{~m}$ & $1 \mathrm{~h}$ \\
\hline
\end{tabular}

Further constraints exist also on the discretization of the wave energy spectrum in spectral wave models with a minimum number of frequencies $(>25)$ and azimuthal directions $(>24)$, as well as on the physical processes considered (in particular the inclusion of bottom friction and wave breaking in nearshore areas) $[15,16]$. In spite of the accuracy reached for the final project design stage, these specifications were applied in a limited number of resource assessments, mainly as they required complex and sophisticated numerical simulations with high computational costs, and validation against extended field measurements [16-19]. The great part of wave power assessments were therefore 
conducted regardless of these specifications. Nevertheless, these resource assessments provided new features and methods to characterize the available resource and its exploitation by WEC $[6,20]$, and an up-to-date review of associated analysis may promote new recommendations and specifications for advanced resource characterizations.

Indeed, resource assessment is not simply a question of approaching, with the highest possible accuracy, wave parameters traditionally considered in coastal wave studies (such as the significant wave height $H_{s}$ or the peak period $T_{p}$ ), and the associated power density. Thus, it requires more detailed characteristics of the sea state including specific output parameters such as (i) the energy period $T_{e}$ used for the computation of wave energy flux [21], (ii) the direction of maximum wave energy transport or (iii) its directional spreading $[13,15,21,22]$. The production of scatter diagrams (that provide the bivariate distribution of the sea states occurrence among wave heights and periods) is furthermore required to estimate the energy output of a WEC system based on its power matrix [6]. Particular attention must also be dedicated to the time scale considered that must be long enough to encompass resource annual and seasonal variabilities [23]. Wave energy resource assessment is therefore a complex multivariable problem that requires a detailed understanding of all influencing parameters by relying on specific statistical analyses, energy metrics and selection indexes [24]. Although a part of these aspects appeared in technical specifications, we proposed here a review of the most recent resource assessments encompassing applications based on (i) available observations (in situ and satellite) and (ii) hindcast databases, and (iii) refined simulations specifically implemented for resource characterization. Our review focused therefore on the basic preliminary investigations of a wave energy project that may pave the way for refined design and advanced testing of full-scale devices [25]. Particular attention was furthermore dedicated to uncertainties in the evaluation of the available and expected powers associated with (i) wave-climate temporal variability, (ii) coastal physical processes (such as wave-current interactions), (iii) model implementation and (iv) energy extraction. Although future wave-climate projections may be exploited to conduct sustainability analysis of WEC in relation to climate change e.g., [26,27], these investigations were disregarded in the present review primary dedicated to hindcast-historical studies that integrate reduced levels of uncertainties. Beyond a simple comparison of advantages and drawbacks of a series of resource studies, this review highlighted the potential of exploiting different data for conducting improved resource assessments, thus promoting original resource characterizations and analyses.

The paper is organized as follows. Section 2 exhibits the specific objectives and methods retained for wave energy characterization. After a description of theoretical formulations traditionally adopted for wave power computation (Section 2.1), particular attention is dedicated to a series of metrics introduced to assess the available resource (pre-production metrics) and the generated power (post-production metrics) (Section 2.2). The review focuses on the annual and seasonal variability of available wave power, the WEC performance and the economic cost of a power generation system. The description of these metrics is complemented by a review of selection indexes considered to reduce uncertainties and biases in WEC design and locations (Section 2.3). Section 3 investigates wave resource assessments based on default available data, traditionally considered in wave studies, focusing on the exploitation of local in situ and satellite observations (Section 3.1), and regional numerical hindcast databases (Section 3.2). Section 4 describes numerical simulations specifically dedicated to wave energy resource assessments with an initial classification based on the spatial scales considered (continental shelf scales, regional scale or local/coastal scale of a wave energy farm) (Section 4.1). More refined assessments including wave and tide coupling or the effects of energy extraction on the wave field are reviewed (Section 4.2).

\section{Wave Energy Characterization}

A wave energy resource assessment primarily focuses on the characterization of (i) dominant metocean conditions (e.g., wind, wave, current and water level) and (ii) energy potential. These are the most important information which determine power production potential, design of devices and 
deployment characteristics. Subsequently, more in-depth analysis can be conducted on the available wave power regarding return resource persistence, power production stability, temporal variability (at annual, seasonal and monthly time scales), climate change effects, etc. These investigations both require (i) the definition of a series of specific output parameters and (ii) the development of energy resource metrics to characterize the resource temporal variability, the device power production and the economic viability of a wave energy project. A review of the main different parameters and metrics was here proposed.

\subsection{Wave Power Computation}

The available wave energy flux (also denominated the wave power density or wave energy potential per unit crest, in $\mathrm{W} \mathrm{m}^{-1}$ ) characterizes the amount of energy reaching a given location. It is defined as the integral of the wave energy spectrum

$$
P=\rho g \int_{0}^{2 \pi} \int_{0}^{\infty} c_{g}(\sigma) E(\sigma, \theta) d \sigma d \theta
$$

where $\rho$ is the density of seawater, $g$ is the acceleration due to gravity, $E$ is the wave energy density distributed over intrinsic frequencies $\sigma$ and propagation directions $\theta$, and $c_{g}$ is the group velocity.

However, the distribution of $E$ over frequencies and directions may be difficult to obtain as most wave studies retain integrated parameters such as the significant wave height and the wave period. In these conditions, simplified formulations were adopted to approach the available wave power density. These formulations require different assumptions whether the application was considered in shallow waters, medium water depths or deep waters [28]. Large-scale assessments of the available resource relied, most of the time, on the deep-water assumption. In deep waters $(k d>>1$ with $d$ the water depth and $k$ the wave number), the group velocity is approximated as $c_{g}=g /(4 \pi f)$ with $f$ the wave frequency, and the formulation (1) is generally rewritten as a function of the significant wave height $H_{s}=4 \sqrt{m_{0}}$ and the wave energy period $T_{e}=m_{-1} / m_{0}$ as

$$
P=\frac{\rho g^{2}}{64 \pi} H_{s}^{2} T_{e}
$$

with $m_{n}=\int_{0}^{\infty} f^{n} E(f) d f$ the $n$th order spectral moment. The wave energy period appears therefore as an important output parameter to approach the wave energy flux in offshore waters. It can be interpreted as the period of a single sinusoidal wave that integrates the same amount of energy as in the real sea state. However, wave parameters from numerical resource assessments (and especially hindcast archives) set aside the energy period $T_{e}$ retaining bulk parameters (such as $H_{s}$ or $T_{p}$ ). For these reasons, the energy period is approximated by relying on available periods such as the mean or peak wave periods, and a calibration coefficient is introduced. For the peak period, this calibration coefficient $\alpha$ is defined such as $T_{e}=\alpha T_{p}$. It is generally estimated by assuming standard shapes of the wave energy spectrum, but may present increased differences in combined sea states including long-crested swell and short-crested wind-sea waves with two energy maxima, in high and low frequencies, respectively. This results in a wide range of values for the assessment of the wave energy resource (Table 2).

$P$ characterizes furthermore the omnidirectional wave power density, and a more refined definition of the available energy and potential power captured by WEC in a given direction may be formulated. Further details about the associated parameters are available in [15]. 
Table 2. Estimations of the calibration coefficient $\alpha$ between the peak period $T_{p}$ and the energy period $T_{e}\left(T_{e}=\alpha T_{p}\right)$.

\begin{tabular}{ccc}
\hline Estimations of $\alpha$ & Methods & References \\
\hline 0.9 & Analytical derivation of a JONSWAP spectrum (peak enhancement $\gamma=3.3)$ & {$[29-31]$} \\
0.86 & Analytical derivation of a Pierson-Moskowitz spectrum & {$[32]$} \\
0.8 & Exploitation of observations in the Atlantic Marine Energy Test Site (Ireland) & {$[33]$} \\
0.86 for wind sea/ & Analytical derivations of Pierson-Moskowitz spectrum & {$[34]$} \\
1.0 for swell & and Gaussian spectrum & {$[21]$} \\
$\in[0.29 ; 1.5]$ & Exploitation of NOAA observations of the North-West Atlantic & \\
\hline
\end{tabular}

\subsection{Wave Energy Metrics}

Wave energy resource assessments rely on metrics that may be applied for evaluations of the available resource (pre-production metrics) and the generated power (post-production metrics), respectively.

\subsubsection{Pre-Production Metrics}

Pre-production metrics aim at characterizing the temporal variability of the wave climate at different time scales (monthly, seasonal or annual). Following Cornett [29] and Gonçalves et al. [35], the coefficient of variation (see Equation (3)) evaluates, at all time scales, the amount of variability with respect to the mean value by dividing the standard deviation of $P\left(\sigma_{P}\right)$ to the mean available wave power $\left(P_{\text {mean }}\right)$ over the period considered (typically several decades):

$$
\mathrm{CoV}=\frac{\sigma_{P}}{P_{\text {mean }}} .
$$

The annual variability index characterizes the intra-annual differentiations in the resource and is defined as

$$
\mathrm{AVI}=\frac{P_{A 1}-P_{A 2}}{P_{\text {year }}}
$$

with $P_{\text {year }}$ the annual mean wave power, and $P_{A 1}$ and $P_{A 2}$ the mean available wave powers for the most and the least energetic years, respectively. This formulation is adapted to approach the seasonal and monthly variability indexes of the available resource with the two following expressions SVI $=\left(P_{S 1}-P_{S 2}\right) / P_{y e a r}$ and MVI $=\left(P_{M 1}-P_{M 2}\right) / P_{\text {year }}$ where $P_{S 1}$ and $P_{S 2}$ are the mean powers for the most and the least energetic seasons, respectively; and $P_{M 1}$ and $P_{M 2}$ are the mean powers for the most and the least energetic months, respectively.

The evolution of available wave energy resource may also be assessed with the rate of change assessing the variation $P$ over a given period of time $T$ as $R C=\Delta P / \Delta T$. This parameter may be particularly useful to compare the evolution of the resource between past decades and future projections that integrate the effects of climate changes. Additional statistical parameters may also be considered such as the joint probability for metocean condition $\left(F\left(H_{s} \cap T_{p}\right)\right.$ and /or $\left.F\left(H_{s} \cap T_{p} \cap P_{\theta}\right)\right)$, and $F(P \geq X)$ quantifying the probability that the available power density remains above a given threshold $X$.

\subsubsection{Post-Production Metrics}

Post-production metrics focus on the evaluation of WEC generated power and performance. The capture width, expressed in $\mathrm{m}$ and defined as $\mathrm{CW}=P_{\text {gen }} / P$ with $P_{\text {gen }}$ the generated power $(\mathrm{kW})$, is generally considered to assess the ability of a device to absorb the available wave energy flux. However, given the wide range of WEC technologies, CW was adapted to represent the diverse solutions resulting in the Cross With Ratio (CWR) expressed as

$$
C W R=\frac{C W}{B}
$$


with B the device characteristic dimension. Babarit [36] introduced this parameter and estimated its value for a variety of WECs in diverse coastal locations, examining differences in energy performance. Since then several studies have relied on this metrics to examine and assess WEC power absorption potential e.g., [37-39]. Estimating wave energy depends, however, on the WEC power matrix PM, which represents the equivalent power curves by providing the energy produced among wave heights and periods. Depending on the WEC technology, geometrical characteristics (size, weight, etc.), response amplitudes and excitation forces will differ; and this will directly influence the power produced by WEC for given metocean conditions [40,41]. According to best practices, estimating WEC energy output requires the combination of wave scatter diagrams with device power matrix as Equation (6)

$$
E_{o}=\sum_{i=1}^{n_{T_{p}}} \sum_{j=1}^{n_{H_{s}}} F\left(H_{s_{i, j}} \cap T_{p_{i, j}}\right) \cdot P M_{i, j} \cdot \Delta T
$$

where $n_{T_{p}}$ and $n_{H_{s}}$ are the number of peak wave periods and significant wave heights classes considered, respectively. Energy production is dependent on rated power $P_{o}$ (installed capacity in KW), suggesting that higher MW WEC will, in absolute terms, generate more electricity.

However, power production is not a metric that allows WEC and cross-technology comparisons. For assessing which device is better to implement in a specific environment and assess it power production capabilities, the capacity factor is considered, see Equation (7)

$$
\mathrm{CF}=\frac{E_{0}}{P_{0} \cdot \Delta T} .
$$

$\mathrm{CF}$ accounts for the fraction of the time the energy converter is operating at full capacity. Higher $\mathrm{CF}$ values account therefore for an improved use of a device in terms of power production whereas lower CF values exhibit improper WEC technologies at the location considered. As in any other renewable energy, the intra-annual, seasonal and monthly variabilities of the wave resource may have a major effect on the capacity factor [6]. CF values thus depend on the adaptability of the WEC technology to a given wave climate. Indeed, high rated WEC will require high energy levels, and will show reduced performance in locations with moderate resources; hence CF is dependent on WEC selection e.g., $[6,24,42]$. Availability of production is another metric that is considered to determine WEC operations between a start limit $P_{\text {in }}$ and an upper limit $P_{\text {out }}$. Such analysis can be considered in different ways, but usually availability refers to start (cut-in) and end (cut-out) thresholds for the useful operation of a WEC [43].

With the capacity factor, the Levelized Cost of Energy (LCoE) (expressed in $€ / M W h$ ) evaluates the economic cost of a power generation system during its lifespan, and may therefore be exploited to compare WEC technologies e.g., [44-46]. It is expressed as Equation (8)

$$
\mathrm{LCoE}=\frac{\mathrm{PV}(\mathrm{CapEx}+\mathrm{OM})-\mathrm{PV}(\mathrm{S})}{\mathrm{AEP}}
$$

with the total project cost capital expenditure (CapEx) and Operation \& Maintenance (OM) minus any potential benefits from salvage (S) values, and AEP the Annual Energy Production, all values being expressed in Present Values (PV). Although LCoE is an indispensable tool that provides a level field for technology comparisons, it does not directly dictate the economic viability of a wave energy project. LCoE can therefore be categorized under economic criteria, which can be more extensive in list with added functions such as the Net Present Value (NPV), Internal Rate of Return (IRR), simple and/or discounted payback periods. However, these parameters are usually looked in depth at later stages of the analysis [47].

Pre- and post- production metrics are part of an overall process that seeks to identify and quantify basic energy, and subsequently economic characteristics of a WEC, reaching to a decision that will either be positive or negative. This simplified linear process analysis requires, at any step of the 
assessment, to go back and retain another WEC to refine the selection, and continuously update the content for the decision maker with the outcome of new economic and energy analysis (Figure 1). WEC techno-economic performance and optimization is therefore inherently dependent on high levels of wave-climate assessments. This is also the case for the selection of a WEC that requires a close match to local wave conditions.

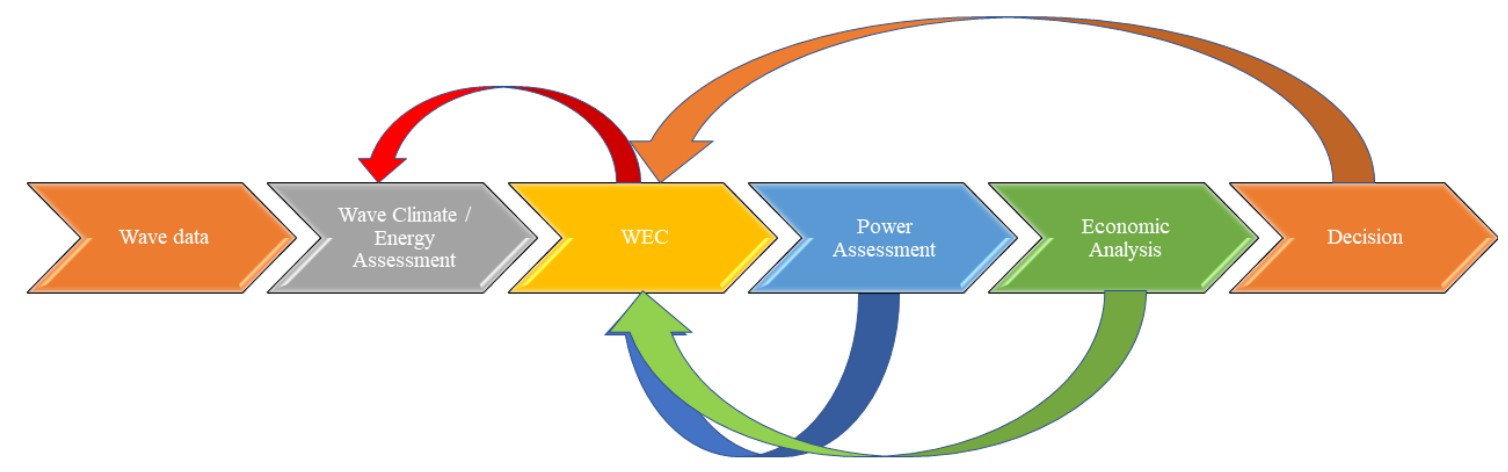

Figure 1. Linear process for the selection of suitable WEC.

\subsection{Selection Indexes}

In effort to optimize the selection of WEC and location in the marine environment, a series of investigations have been suggested to reduce the uncertainties in wave energy resource assessments, with the development of indices/methodologies dedicated to the decision making process. Such kind of indices can be separated into (i) resource-based indices dedicated to resource classification and (ii) hybrid approaches dedicated to quantification of both resource and WECs generated powers.

\subsubsection{Resource-Based Indices}

Hagerman [48] proposed a selection index that considers the ratio of the mean annual energy flux $P_{y e a r}$ to the highest (storm) energy flux potential $J_{P}$ called the Wave Energy Development Index (WEDI)

$$
\mathrm{WEDI}=\frac{P_{\text {year }}}{J_{P}}
$$

suggesting that the higher WEDI is, then a more severe design penalty is expected to affect CapEx. The method has been examined in several regions including parts of the Mediterranean Sea $[46,49,50]$.

An Optimum Hotspot Identifier (OHI) (see Equation (10)) was suggested by Kamranzad et al. [51] and applied to the Persian Gulf. The method takes into account the mean wave energy content, an availability factor that the authors set at $2 \mathrm{kWm}^{-1}$, and the Monthly Variability Index (MVI, Section 2.2.1)

$$
\mathrm{OHI}=\frac{P_{\text {year }} \cdot F\left(P>2 \mathrm{kWm}^{-1}\right)}{\mathrm{MVI}} .
$$

Ahn et al. [52] proposed an inter-annual variability index (see Equation (11)) that accounts for the standard deviation of energy production as

$$
t_{i}=\frac{\sigma\left[E(Y)-\left(S_{1} Y+S_{2}\right)\right]}{E_{\text {year }}} \cdot 100 \%
$$

with $E_{\text {year }}$ the theoretical available annual wave energy averaged over the years considered for the resource assessment. The method uses a linear regression $\left(S_{1}\right)$ and a slope coefficient $\left(S_{2}\right)$ to examine the variation of the theoretical available wave energy $E(Y)$ of year $Y$. The index suggests that a high value of $t_{i}$ reveals a large variability of the available wave energy resource. This index was applied at the USA coastlines. 


\subsubsection{Hybrid Method Based Indices}

Kamranzad and Hadadpour [53] suggested a Multi-Criteria Approach (MCA) for selecting a WEC based on various criteria (see Equation (12)). The suggested index integrates a mix of energy production, accessibility and availability percentages, and MVI conditions for WEC energy output $E_{o}$ :

$$
\text { MCA }=\frac{\frac{E_{e}}{2000} \cdot \text { accessibility } \cdot \text { availability } \cdot \frac{E_{o}}{10000} \cdot \frac{5}{H_{s, 100}}}{\operatorname{MVI}_{E_{o}}}
$$

with $E_{e}$ the exploitable storage of wave energy per unit area and $H_{s, 100}$ the design wave height for 100 years return period. This index should complement policy considerations, by selecting location with higher MCA values. The study was applied on a series of state-of-the-art WECs at the Caspian Sea and Oman Gulf.

Lavidas [24] suggested the Selection Index for Wave Energy Deployments (SIWED) following the formulation

$$
\text { SIWED }=\frac{e^{-\mathrm{CoV}_{H_{s}} \cdot \mathrm{CF}}}{\frac{H_{E V A}}{H_{\max }}}
$$

with $\mathrm{CoV}_{H_{s}}$ the Coefficient of Variation of the significant wave height $H_{s}=4 \sqrt{m_{0}}$, CF the capacity factor, $H_{E V A}$ the value of return waves based on extreme value analysis, and $H_{\max }$ the maxima value of wave height from the dataset. The index reduces uncertainties and bridges the power capabilities with resource dependence, providing an unbiased selection of WEC. It was first applied in the North Sea to compare different WECs technologies. A region with high variability accounts for penalized power performance, since a higher volatility indicates a potential larger rate of change in metocean conditions. At the denumerator, the ratio of extreme return wave value over the maximum significant wave height quantifies WEC survivability. When SIWED obtains a higher value, that means the site and selected WEC have a better "match" and can deliver reliable energy production.

It is important to note that use of any index does not exclude expert judgement, and when using any type of index the user has to be cautious of not using quantities that replicate themselves in the formulae and that index limitations are understood, whether these are resource or WEC-based. Table 3 provides a summative description of discussed indices, focusing on wave energy unique ones and these which can be statistically inferred.

Table 3. List of specific indices for wave energy applications, hybrid implies a combination of resource and power production characteristics.

\begin{tabular}{ccc}
\hline Types & Indexes & References \\
\hline Resource & Wave Energy Development Index (WEDI) & {$[48]$} \\
Resource & Optimum Hotspot Identifier (OHI) & {$[51]$} \\
Resource & Inter-annual variability $\left(t_{i}\right)$ & {$[52]$} \\
Hybrid & Cross Width (CW) & {$[54]$} \\
Hybrid & Cross Width Ratio (CWR) & {$[36]$} \\
Hybrid & Multi-Criteria Approach (MCA) & {$[53]$} \\
Hybrid & Selection Index for Wave Energy Deployments (SIWED) & {$[24]$} \\
\hline
\end{tabular}

\section{Exploitation of Available Data}

There exists a series of available data to characterize the wave energy conditions in the marine environment. This includes observations from in situ devices such as wave buoys or remote-sensing measurements from satellite altimeters, but also hindcast databases and reanalysis archives obtained from the implementation of large-scale numerical wind-wave models. Observations are traditionally considered to assess model performance while hindcast databases are exploited to provide input boundary conditions for nested refined simulations in shallow waters. However, the historical recorded 
and/or simulated characteristics of the sea state include also valuable information about wave power variability, which is very easy to access and may be useful in the preliminary stages of a wave energy project. We reviewed here the specifics associated with the exploitation of these available data for wave energy resource assessments.

\subsection{Observations}

\subsubsection{In Situ Measurements}

Although in situ observations are scarce in locations retained for wave energy exploitation, these data that correspond to the real environmental conditions may provide a valuable source of information to characterize the available resource. Indeed, recorded observations show, most of the time, a high-temporal resolution and a good sampling (in the range of 10-30 $\mathrm{min}$ ) in the output parameters. Two types of datasets are traditionally available: standard integrated wave parameters $\left(H_{s}, T_{p}, T_{e}\right.$, etc.) and spectral wave data (typically the wave energy density over frequencies, and/or over frequencies and directions depending on the directional/omnidirectional capabilities of wave measuring buoys). In situ observations have been exploited in resource assessments to (i) refine the quantification of available wave power (based on real sea conditions), (ii) exhibit waves temporal variability (trends in wave heights, periods, power, etc.), and (iii) evaluate the reliability of simplified wave power formulations based on integrated parameters (such as peak or mean wave periods) e.g., $[21,55,56]$.

These evaluations were, most the time, conducted by relying on a network of available wave buoys. A part of these investigations were conducted in the North-West Atlantic characterized by a high spatial coverage of NDBC wave buoys (National Data Buoy Center-National Oceanic and Atmospheric Administration-NOAA) with observation acquired for more than 15 years in several coastal and offshore locations [57]. The exploitation of these observations exhibited the differences in the available wave energy flux between the energetic oceanic areas and the semi-enclosed basins (the Gulf of Mexico and the Carribean Sea) [21,55]. Beyond an evaluation of the spatial distribution of mean available wave power, these resource assessments highlighted temporal variability. By exploiting wave-buoy measurements around the Florida peninsula, Ozkan and Mayo [56] assessed the annual variability of available power, thus identifying the locations with the highest variations and the strongest intermittency in energy production. In the Gulf of Mexico, correlations were established between the El Nino indices and the significant wave height suggesting increases in available wave power during El Nino seasons over the coming decades. The seasonal trends in wave height and associated power were also exhibited by Defne et al. [55] in measurements locations along the Atlantic coast of the southeastern USA revealing a regular pattern of every 3-4 years for the occurrence of extreme conditions in September, seemingly associated with tropical weather systems. Investigations were furthermore conducted in other marine environments such as in the East China Sea where Wu et al. [58] exploited wave-buoy observations at six offshore locations to characterize seasonal trends in available wave power and directions.

The exploitation of in situ observations was also particularly useful to assess uncertainties associated with simplified formulations of the available wave power density based on significant wave height and default statistical periods (such as $T_{p}$, the mean period $T_{m}$ or the zero-crossing mean period $T_{z}$ ) (Section 2.1). These aspects are fundamental as a great number of numerical wave energy resource assessments rely on these simplified formulations to investigate the potential of a marine area for energy exploitation. In deep waters, these resource assessments require therefore to establish the relationship between the energy period $T_{e}$ and default wave periods which are traditionally available in remote-sensing analysis and hindcast databases (Sections 3.1.2 and 3.2). However, as exhibited in Section 2.1, there exists a relative uncertainty in the estimation of the calibration coefficient (between these default wave periods and the energy period) which directly impacts the estimation of the available wave energy flux. By exploiting NDBC wave-buoy observations along the Atlantic coast of 
the southeastern USA, Defne et al. [55] exhibited that a formulation of wave power density based on $H_{s}$ and $T_{m}$ (without correction factor) tended to overestimate the available wave energy density and that it was necessary to apply a calibration coefficient of 0.61 to obtain the best regression between the spectral and simplified formulations of the wave energy flux. More recently, Guillou [21] showed that a formulation based on $H_{s}$ and $T_{p}$ (with a default calibration coefficient $\alpha=0.9$ matching JONSWAP spectrum) overestimated the yearly averaged available wave energy flux with differences exceeding locally $8 \%$. In spite of reduced differences in the estimation of averaged quantities, the calibration coefficient was also characterized by important temporal variations estimated between 0.3 and 1.7, and different values were retained in wave energy resource assessments (Table 2). However, $\alpha$ was found to follow tendencies with respect to classes of $H_{s}$ and $T_{p}$ (Figure 2).

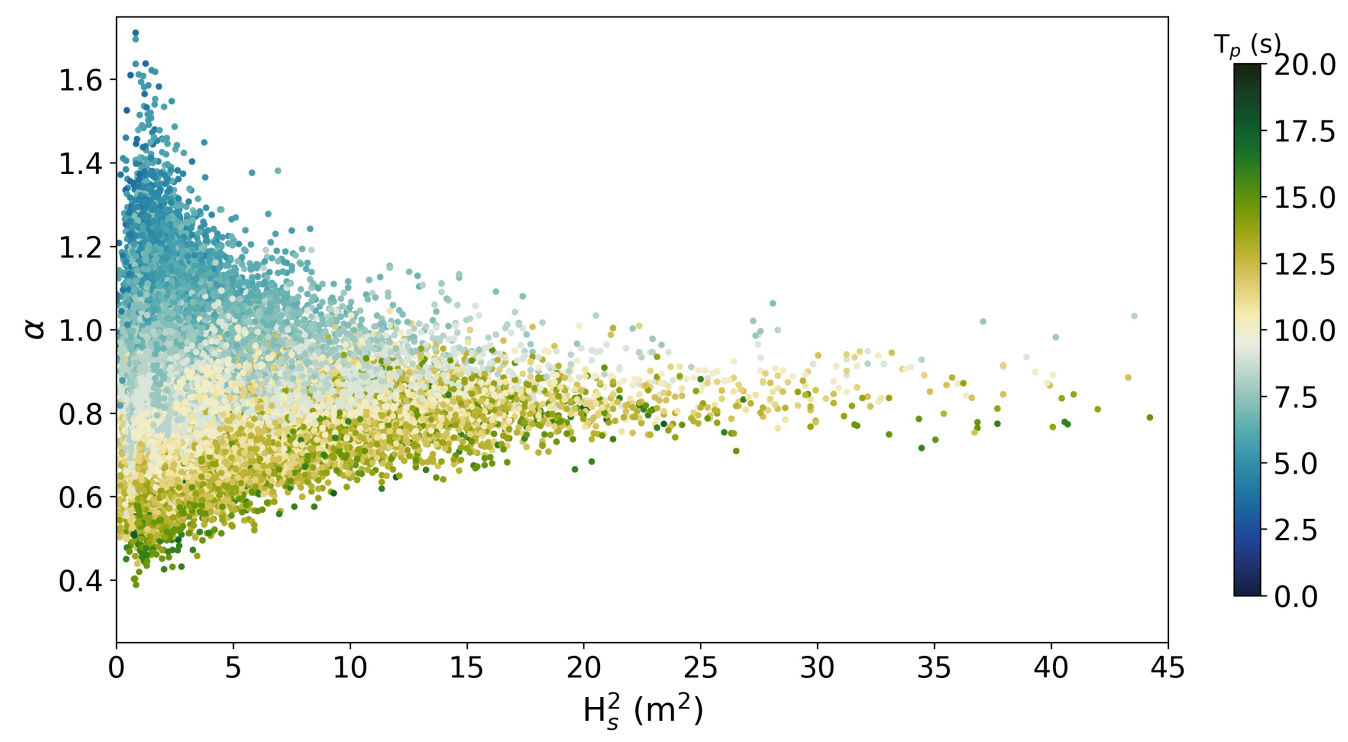

Figure 2. Evolution of the calibration coefficient $\alpha$ between $T_{e}$ and $T_{p}\left(T_{e}=\alpha T_{p}\right)$ with respect to the significant wave height $H_{s}$ squared and the peak period $T_{p}$ at NDBC wave buoy 41,046 off the Bahamas (North-West Atlantic) adapted from [21].

The calibration coefficient $\alpha$ between $T_{e}$ and $T_{p}$ was thus found to converge to values around 0.8 and 0.9 for the most energetic sea states whereas more dispersion was obtained in reduced energy levels, with values between 0.3 and 1.7 [21]. By agglomerating observations at 17 locations in the North-West Atlantic, a refined distribution of $\alpha$ against classes of $H_{s}$ and $T_{p}$ was established to reduce the differences between the spectral formulation (Equation (1)) and the simplified formulation (Equation (2) with evaluation of the energy period as $T_{e}=\alpha T_{p}$ ), decreasing the relative difference from $9.9 \%$ to $0.3 \%$ off the Greater Antilles (North-West Atlantic) (Figure 3). 


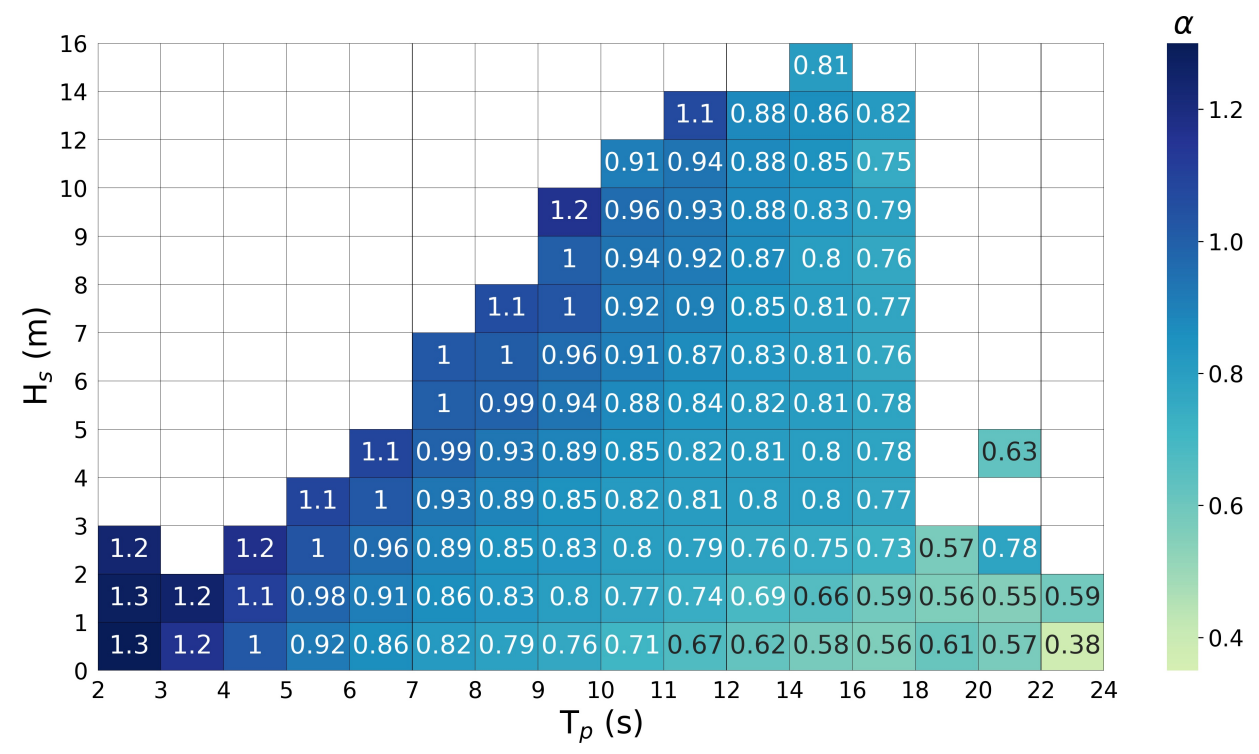

Figure 3. Distribution of the calibration coefficient $\alpha$ in classes of $H_{s}$ and $T_{p}$ resulting from the integration of observations in 17 NDBC wave buoys of the North-West Atlantic adapted from [21].

\subsubsection{Satellite Observations}

With orbital periods of around 10-35 days, widely spared ground tracks (over hundreds of kilometers) and uncertainties particularly pronounced in the vicinity of the coastline, satellite observations show important spatial and temporal limitations for assessing the available wave energy resource. However, these remote-sensing measurements were able to image through clouds and provide day-and-night data. Satellite represents furthermore a long-term and extensive monitoring of the sea state. The exploitation of these large-scale observations, most of the time integrated in publicly available databases, is thus liable to produce spatial maps of the wave energy density at any location in the world. These maps may derive from a combination of multi-satellite altimeters to produce a large-scale synoptic representation of the mean power density and/or associated energy metrics. Individual satellite passes may also be exploited to obtain, at high spatial resolution, along-track maps of wave energy density in coastal "hot spots" [59]. Satellite observations represent therefore an interesting alternative to local in situ measurements or time-consuming numerical simulations.

Two types of space-born radars may be considered for resource characterization: (i) altimeter which measures the time taken by a radar pulse to travel from the satellite to the sea surface and return, and (ii) Synthetic Aperture Radar (SAR) which exploits a large bandwidth of the electromagnetic spectrum $[60,61]$. Although SAR increases the spatial resolution of observations and gives access to the wave energy spectrum, the great number of wave energy assessments based on satellite observations relies on altimetry [28]. Indeed, the exploitation of satellite altimeters provides (i) an evaluation of the significant wave height and associated wave power in coastal locations considered for WEC setup (where wave-buoy measurements are not always available), and (ii) preliminary assessments of the temporal variability of the wave climate.

Satellite altimetry may thus reach accurate evaluations of $H_{s}$ being comparable to local wave buoy observations $[62,63]$. However, altimeter data does not integrate the wave period, and a series of inversion models are required to derive wave period from satellite observations with specific field of applications and calibration data [64-67]. This resulted in less good estimates of the wave period that the significant wave height. By comparing satellite altimeter data with wave-buoy measurements in the South China Sea, Yaakob et al. [68] obtained thus correlation coefficients of 0.885 for the peak period and 0.931 for the significant wave height, with RMSE of $0.217 \mathrm{~m}$ for $H_{s}$ and $0.993 \mathrm{~s}$ for $T_{p}$ matching typical errors of altimeter-buoys comparisons [69,70]. The inversion models are furthermore restricted to traditional wave parameters such as $T_{p}$ or $T_{z}$, which requires further assumptions about 
the relationship between the energy period and these wave periods to estimate the available wave power density (see Sections 2.1 and 3.1.1 for further details). Nevertheless, as the available wave power density depends on the square of $H_{S}$ (Equation (2)), reduced differences are obtained in wave energy resource assessments based on satellite observations. Mackay et al. [59] thus showed that measurements derived from a combination of satellite altimeters was able to reproduce the evaluation of power from a Pelamis device in NDBC wave buoys of the western and eastern coasts of North America. More recently, Goddijn-Murphy et al. [71] obtained negligible differences between the mean power derived from Altika satellite and wave-buoy measurements at two locations in the Farr Bay (North Scotland). Restricted satellite sampling may finally have a marked effect on the estimation of available power, especially in areas where the resource shows high temporal variability. However, data sampling was found to impact mainly the evaluation of peak power and differences in annual mean wave power were found to decrease with the number of year of observations [59]. This promotes the exploitation of satellite measurements for the evaluation of mean wave energy quantities rather than the highest values.

Satellite altimeter data acquisition started furthermore in the mid-eighties (with the launch of Geostat) giving today access to measurements over decades. The exploitation of satellite data from several past and present altimeter missions (e.g., ENVISAT, TOPEX/Poseidon, Jason-1, Jason-32, etc.) provided thus first large-scale assessments of the annual and seasonal variabilities of the wave energy resource based on observations (Table 4).

Table 4. Non-exhaustive review of satellite altimeters databases exploited for wave energy resource assessments.

\begin{tabular}{|c|c|c|c|c|}
\hline Satellite Databases & Application Areas & Time Ranges & Spatial Resolutions & References \\
\hline $\begin{array}{l}\text { AVISO multi-satellite } \\
\text { merged data }\end{array}$ & $\begin{array}{c}\text { China'seas/ } \\
\text { Northwest Pacific }\end{array}$ & 2009-2013 & $1^{\mathrm{o}} \times 1^{\circ}$ & [28] \\
\hline Multi-satellite altimeters & North Atlantic & 1996-2005 & $2^{\circ} \times 2^{\circ}$ & [59] \\
\hline ENVISAT & Indonesia & 2010-2011 & - & [72] \\
\hline ENVISAT & Indonesia & 2002-2012 & - & [73] \\
\hline Altika & North Scotland & 2014 & $11 \mathrm{~km} \times 5 \mathrm{~km}$ & [71] \\
\hline Multi-satellite altimeters & South China Sea & $2001-2010$ & $0.25^{\circ} \times 0.25^{\circ}$ & [68] \\
\hline
\end{tabular}

By exploiting five-year AVISO observation data merged from multi-altimeter satellites, Wan et al. [28,74] characterized the temporal variability of the wave resource in the China's seas and Northwest Pacific producing a series of cartographies based on energy metrics CoV, SVI and MVI. Whereas numerous investigations have been conducted in these areas since the 1980s, this was the first wave energy resource assessment based on satellite observations in this region. Yaakob et al. [68] exploited also a 10-year database retrieved from a combination of multi-satellite altimeters to characterize (i) the wave energy resource in the South China Sea (focusing on the Malaysian region) and (ii) the wave climate with a series of $H_{s}-T_{p}$ scatter diagrams in specific locations. Beyond a simple evaluation of the mean available wave power density identifying areas with the highest energy, such exploitation of satellite altimeter data provided valuable information for WEC design and performance. And we may expect increased accuracy of wave energy resource assessment with the exploitation of an increased historical amount of satellite observations.

\subsection{Hindcast Databases and Reanalysis Archives}

The exploitation of available hindcast databases and reanalysis archives, derived from large-scale numerical wave simulations, may be of interest in the reconnaissance stage of a wave energy project saving time in the implementation, computation and validation of refined simulations dedicated to resource assessment. Validated and assimilated against a series of in situ and satellite observations, these datasets reach good estimations of the wave conditions in offshore waters. Wave hindcasts and reanalysis archives cover furthermore long periods of time, typically between 30 and 60 years, 
offering a longer temporal coverage than satellite measurements and providing (according to the technical specifications) valuable information to (i) investigate the temporal variability of the wave energy resource at monthly, seasonal and annual time scales, and (ii) exhibit the long-term evolutions by identifying decadal changes in wave power density [75] (Table 5).

Table 5. Non-exhaustive review of wave hindcast databases and reanalysis archives exploited in wave energy resource assessments.

\begin{tabular}{cccccc}
\hline $\begin{array}{c}\text { Hindcast } \\
\text { Databases }\end{array}$ & Application Areas & Time Ranges & $\begin{array}{c}\text { Spatial } \\
\text { Resolutions }\end{array}$ & $\begin{array}{c}\text { Output } \\
\text { Time Steps }\end{array}$ & Exploitations \\
\hline HIPOCAS $^{1}[76]$ & North Atlantic $\rightarrow$ Spain & $1958-2001$ & $2^{\circ} \rightarrow 0.25^{\circ}$ & $3 \mathrm{~h}$ & {$[31,77]$} \\
CAWCR $^{2}$ [78] & South Pacific and Australia & $1979-2010$ & $0.4^{\circ} \rightarrow 0.07^{\circ}$ & $1 \mathrm{~h}$ & {$[79]$} \\
GOW $^{3}$ [80] & Global & $1948-2008$ & $1.5^{\circ} \times 1^{\circ}$ & $1 \mathrm{~h}$ & {$[75]$} \\
ERA-Interim [81] & Global & $1979-2012$ & $0.75^{\circ}$ & $6 \mathrm{~h}$ & {$[82]$} \\
NCEP [83] & Global/nested domains & $1979-2009$ & $0.5^{\circ} \rightarrow 0.07^{\circ}$ & $3 \mathrm{~h}$ & {$[57]$} \\
NOAA [84] & Global/nested domains & $1997-2006$ & $0.5^{\circ} \rightarrow 0.07^{\circ}$ & $3 \mathrm{~h}$ & {$[1,29]$} \\
\hline \multicolumn{4}{c}{${ }^{1}$ Hindcast of Dynamic Processes of the Ocean and Coastal Areas of Europe. ${ }^{2}$ Centre for Australian Weather } \\
\multicolumn{2}{l}{ and Climate Research. ${ }^{3}$ Global Ocean Wave calibrated reanalysis. }
\end{tabular}

Available in the most energetic shelf sea environments around the world (even in areas where no site measurements or wave recording devices exist), these databases were exploited to characterize the wave energy resource (i) at the worldwide scale e.g., $[1,29,75]$, (ii) over shelf sea environments e.g., [57,82], (iii) along the coastline e.g., [79,85] or (iv) in more restricted areas such as islands e.g., $[77,86]$. Some of these applications are briefly described hereafter. At the worldwide scale, Reguero et al. [75] relied on the 61-year Global Ocean Wave (GOW) calibrated reanalysis (1948-2008) to provide an updated assessment of the global wave power while exhibiting the correlation between wave power and prominent climate indices. At the scale of shelf sea environments, Guillou and Chapalain [57] exploited the 31-year hindcast database (1979-2009), implemented by the National Centers for Environmental Prediction (NCEP), to characterize with a series of energy metrics the annual, seasonal and monthly variabilities of wave power density in the North-West Atlantic, the Gulf of Mexico and the Caribbean Sea (Figure 4). Along the Australian coast, Hemer et al. [79] relied on the 32-year wind-wave hindcast (1979-2010) developed by the Centre for Australian Weather and Climate Research (CAWCR) to characterize, with a refined spatial resolution of $1 / 15^{\circ}(\simeq 7 \mathrm{~km})$, the available wave energy resource at depth contours of 25, 50 and $200 \mathrm{~m}$. The 44-year Hindcast of Dynamic Processes of the Ocean and Coastal Areas of Europe (HIPOCAS) database (1958-2001) was also exploited to characterize the wave energy resource around the Canary Islands (Spain) [77] or along the coast of France in the bay of Biscay [31] exhibiting the wave power variability and producing a series of scatter diagrams to refine WEC designs and locations in these areas.

Nevertheless, apart from a few exceptions such as the CAWCR around Australia, these databases integrate, most of the time, bulk parameters (such as $H_{s}$ or $T_{p}$ ) setting aside a detailed assessment of the wave energy spectrum or the available wave energy flux, mainly as both quantities require extended storage spaces. Following the method adopted in the exploitation of satellite observations (Section 3.1.2), the available wave power density was therefore estimated with the deep-water formulation adopting a constant calibration coefficient between the energy period and the peak or mean periods (Section 2.1, Equation (2)). Most of hindcast databases rely furthermore on the phase-averaged models WAve Model (WAM) or WaveWatch III (WWIII) $[87,88]$, predominantly used in large-scale oceanic domains. Beyond the limitations for coastal applications associated with source terms parameterizations, numerical schemes or computational requirements [20], hindcast simulations are also performed with coarse spatial resolutions that appear insufficient to (i) capture the topographic complexity of most coastlines and (ii) approach processes at refined spatial scales including definition of fetch length, depth-induced refraction or energy dissipation by bottom friction. In spite of embedded computational domains, the hindcast data tend therefore to be less reliable near the coastal area primary targeted for the implementation of energy converters. These nested domains 
cover furthermore the most developed countries with scarce applications in Africa, Asia and South America where opportunities may arise to exploit the wave resource. Further uncertainties exist also, due to the resolution of the input wind fields, in the simulation of tropical cyclones, hurricanes and typhoons, and the exploitation of wave hindcasts can hardly capture these extreme events. For these reasons, refined simulations specifically dedicated to wave energy resource assessments are required to complement these large-scale investigations.
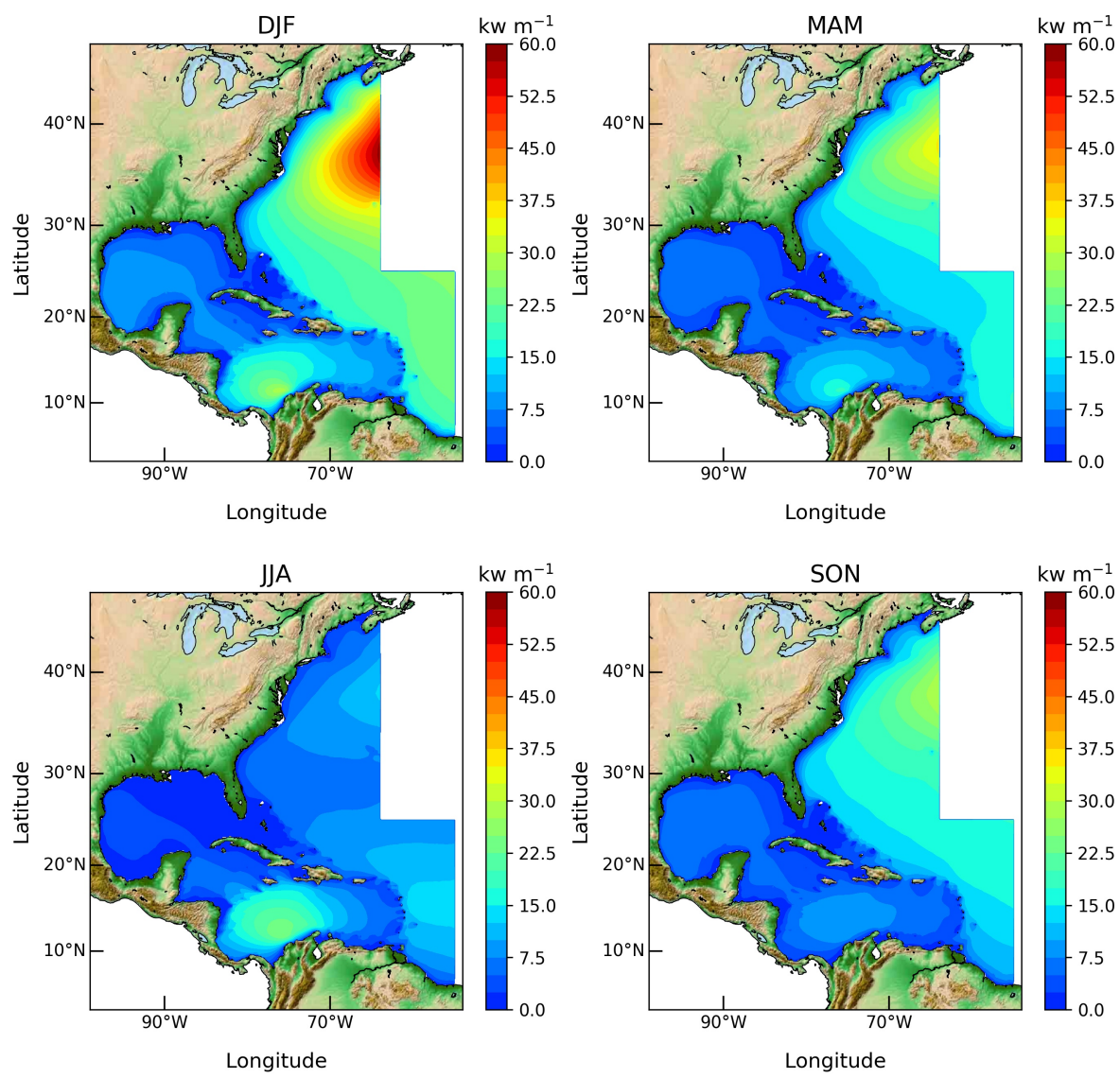

Figure 4. Seasonal evolutions of the mean available wave energy flux in the North-West Atlantic, the Gulf of Mexico and the Caribbean Sea over the period 1979-2009 (DJF = December-January-February, MAM = March-April-May, JJA = June-July-August, SON = September-October-November) adapted from [57].

\section{Numerical Simulations}

As exhibited in the previous section, investigations based on available data relied, most of the time, on the simplified deep-water formulation (Equation (2)) established with a series of assumptions associated with the sea state, significant wave height, wave length and/or water depths [89]. These formulations show, in particular, several limitations for accurate resource assessments in shallow water where waves are impacted by a series of physical processes such as bottom friction, depthand current-induced refraction, shoaling or triads interactions. Available observations and hindcast databases are furthermore characterized by reduced spatial and/or temporal resolutions resulting in a coarse definition of physical processes impacting wave propagation in shallow water.

Although these approaches may be useful in the first step of a wave energy project, refined assessments of the wave resource must be conducted by relying on dedicated numerical simulations. Indeed, numerical wave models are power tools that, if used properly, can offer a plethora of valuable spectral information, reducing uncertainties in wave energy resource assessments. Given the minimum duration of necessary data, we gathered all literature associated with wave energy estimation from 
use of numerical wave models. Our focus was put on scientific studies that integrated an extended description of the calibration and validation procedures. Although other wave-climate databases exist (usually under commercial status), our analysis focused on specific topic publications addressing wave energy resource assessments. In total more than one hundred studies were gathered, predominantly applied in the European shelf seas where a considerable number of technological devices was developed and tested (Figure 5). We here reviewed the different numerical modelling considered for wave energy resource assessments, considering (i) basic simulations dedicated to compute the power density from the distribution of energy spectrum over frequencies and directions and (ii) more complex approaches that integrated the effects of tidal currents or WEC energy extraction on the wave field.

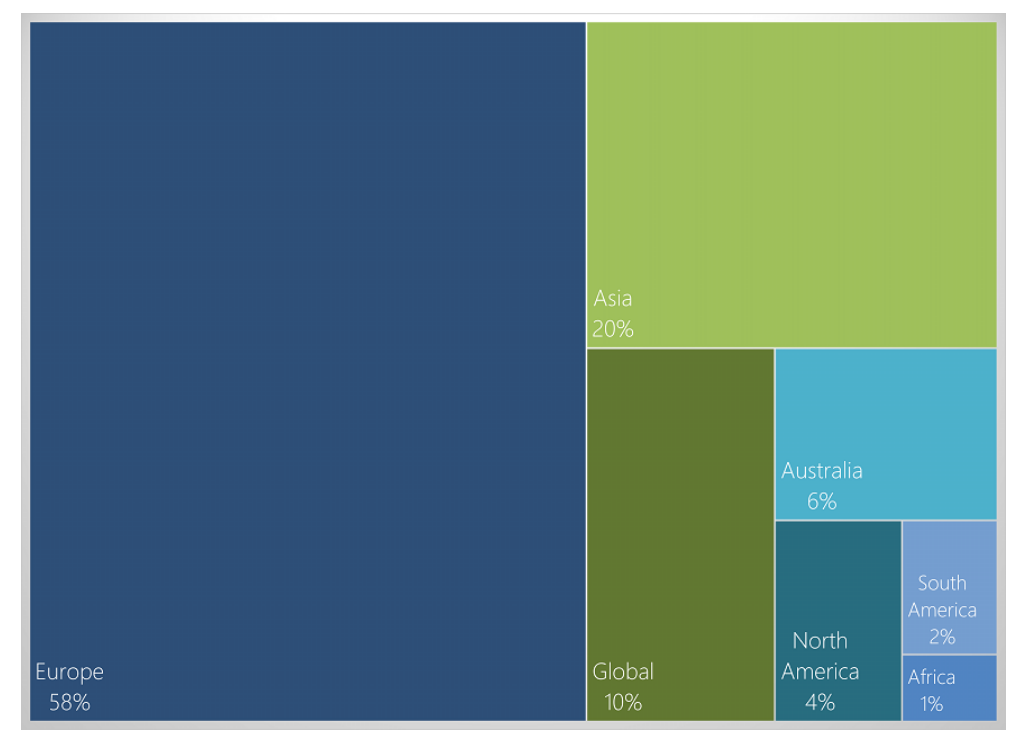

Figure 5. Regional focus of simulations dedicated to wave energy resource assessments.

\subsection{Spatial Scales of Wave Energy Simulations}

The propagation of wind-generated surface-gravity waves from offshore ocean to the continental shelf and shallow waters is computed with phase-averaged spectral wave models that resolve the evolution of the wave energy density integrating the processes of generation, dissipation and nonlinear wave-wave interactions. A review of the latest development of state-of-the-art numerical wave models applied to resource assessment is available in Lavidas and Venugopal [20]. To be consistent with the IEC standards (Section 1), we proposed here a classification of these investigations considering three spatial scales: (i) the continental shelf scale considered in the preliminary stages of resource assessment, (ii) the regional scale dedicated to resource refinement along the coastline of a marine country, and (iii) the local/coastal scale that focuses on the wave energy farm. The spatial scale retained impacts naturally the resolution of the computational grid and the wave model.

\subsubsection{Shelf-Scale Investigations}

Apart from a few exceptions e.g., [90], shelf-scale investigations were mainly conducted by relying on the WAM or WWIII models with spatial resolutions between $1 / 10$ and $1 / 5^{\circ}$ (Table 6 ). These investigations resulted in long-term assessments of the wave energy resource (covering decades) complementing studies based on the exploitation of available hindcast databases and reanalysis archives (not initially developed for wave resource assessment) (Section 3.2). For instance, Wang et al. [91] conducted a 30-year simulation based on WWIII in the South China Sea, thus exhibiting the annual, seasonal and monthly patterns of the wave potential and characterizing the available energy with respect to $H_{s}-T_{p}$ classes as a first benchmark regarding future WEC design in this region. 
Table 6. Examples of shelf-scale numerical wave energy resource assessments.

\begin{tabular}{ccccccc}
\hline $\begin{array}{c}\text { Application } \\
\text { Areas }\end{array}$ & $\begin{array}{c}\text { Wave } \\
\text { Models }\end{array}$ & $\begin{array}{c}\text { Wave Power } \\
\text { Formulations }\end{array}$ & $\begin{array}{c}\text { Types of } \\
\text { Mesh }\end{array}$ & Time Ranges & $\begin{array}{c}\text { Spatial Resol. } \\
\text { Reached }\end{array}$ & References \\
\hline NW European seas & WAM & Deep-Water & Regular & $1987-1994$ & $3^{\circ}$ & {$[92]$} \\
NW European seas & SWAN & Deep-Water & Regular & $2005-2011$ & $0.2^{\circ} \rightarrow 0.04^{\circ}$ & {$[90]$} \\
South China Sea & WWIII & Deep-Water & Regular & $1986-2015$ & $0.2^{\circ}$ & {$[91]$} \\
Mediterranean Sea & WWIII & Deep-Water & Regular & $1979-2013$ & $0.13^{\circ} \times 0.09^{\circ}$ & {$[93]$} \\
\hline
\end{tabular}

\subsubsection{Regional Scale Investigations}

The regional scale may typically cover internal seas (such as the Red Sea [94]), part of the shelf with emphasis on the coastline (such as the Libyan coast in the Mediterranean Sea [46]) or a group of prominent islands (such as in Indonesia [95]) (Table 7). Given the potential influence of shallow-water processes such as bottom friction or refraction, numerous investigations relied on coastal models like the Simulated WAves Nearshore model (SWAN) [96]. With respect to shelf-scale investigations, the computational grid remained regular with spatial resolutions between 0.01 and $0.05^{\circ}$ (from around 1 to $5 \mathrm{~km}$ ). The available wave power may furthermore be estimated with the spectral formulation (Equation (1)) given the limitation of the deep-water assumption for shallow-water locations. In spite of increased spatial resolutions (and similar discretization in frequencies and directions) than in shelf-scale investigations, these resource assessments may cover several decades. Amarouche et al. [97] implemented thus a 39-year wave simulation based on SWAN along the Algerian basin by adopting a spatial resolution of $0.033^{\circ}(\simeq 3 \mathrm{~km})$. Predictions, assessed against a series of six coastal wave-buoy observations, were exploited to identify the area with the highest WEDI index (Equation (9)) and exhibit the high wave potential of the eastern coast of Algeria.

Table 7. Examples of regional numerical wave energy resource assessments.

\begin{tabular}{|c|c|c|c|c|c|c|}
\hline $\begin{array}{c}\text { Application } \\
\text { Areas }\end{array}$ & $\begin{array}{l}\text { Wave } \\
\text { Models }\end{array}$ & $\begin{array}{l}\text { Wave Power } \\
\text { Formulations }\end{array}$ & $\begin{array}{c}\text { Types of } \\
\text { Mesh }\end{array}$ & Time Ranges & $\begin{array}{c}\text { Spatial Resol. } \\
\text { Reached }\end{array}$ & References \\
\hline Gulf of Oman & SWAN & Deep-Water & Regular & 1985-2007 & $0.0333^{\circ}$ & [98] \\
\hline Uruguayan shelf & WWIII & Spectral & Regular & 1980-2015 & $0.02^{\circ}$ & [99] \\
\hline Red Sea & WWIII & Deep-Water & Regular & 1979-2010 & $0.03^{\circ}$ & [94] \\
\hline Indonesia & WWIII & Deep-Water & Regular & 2011-2017 & $0.05^{\circ}$ & [95] \\
\hline North Sea & SWAN & Spectral & Regular & 1980-2017 & $0.025^{\circ}$ & [100] \\
\hline Black Sea & SWAN & Deep-Water & Regular & 1995-2009 & $0.02^{\circ}$ & [101] \\
\hline Persian Gulf & SWAN & Deep-Water & Regular & $1984-2008$ & $0.2^{\circ}$ & [102] \\
\hline Caspian Sea & SWAN & Spectral & Regular & 2009 & $0.08^{\circ}$ & [103] \\
\hline Western France & SWAN & Spectral & Regular & $1998-2000$ & $0.0083^{\circ}$ & [104] \\
\hline Aegean Sea & SWAN & Spectral & Regular & 1980-2014 & $0.025^{\circ}$ & [105] \\
\hline Libyan Sea & SWAN & Spectral & Regular & 1980-2014 & $0.025^{\circ}$ & [46] \\
\hline South Africa & SWAN & Spectral & Regular & 1998-2014 & $0.041^{\circ}$ & [106] \\
\hline Algerian coast & SWAN & Deep-Water & Regular & $1979-2017$ & $0.033^{\circ}$ & [97] \\
\hline Korean Seas & SWAN & Deep-Water & Regular & 2007-2018 & $0.05^{\circ}$ & [107] \\
\hline
\end{tabular}

\subsubsection{Coastal Scale Investigations}

Coastal investigations relied mainly on state-of-the-art shallow-water wave models such as SWAN, MIKE21 [108] or TOMAWAC [109] (Table 8). These resource assessments adopted furthermore spatial resolutions of a few hundreds of meters in the area of interest with (i) embedded simulations based on a series of nested computational domains and/or (ii) unstructured computational grids liable to capture the complex coastline geometry around headlands and islands. As a result of the increased number of grid nodes, these simulations covered generally a restricted period of time, but succeeded in modelling the evolution of the wave condition for a minimum period of 10 years following IEC recommendations. Indeed, given the potential effect of climate change on the evolution of the wave 
resource, a simulation over the most recent decade was considered to be a reliable basis to characterize the temporal variability of the wave energy in coastal locations. Ramos and Ringwood [110] conducted thus a 10-year simulation based on SWAN reaching a spatial resolution of $85 \mathrm{~m}$ in the Belmullet Wave Energy Test Site along the Irish West Coast. However, the refined spatial resolution required important computational efforts, and it was suggested to consider lower resolutions to characterize wave seasonality.

Table 8. Examples of coastal numerical wave energy resource assessments.

\begin{tabular}{ccccccc}
\hline $\begin{array}{c}\text { Application } \\
\text { Areas }\end{array}$ & $\begin{array}{c}\text { Wave } \\
\text { Models }\end{array}$ & $\begin{array}{c}\text { Wave Power } \\
\text { Formulations }\end{array}$ & $\begin{array}{c}\text { Types of } \\
\text { Mesh }\end{array}$ & Time Ranges & $\begin{array}{c}\text { Spatial Resol. } \\
\text { Reached }\end{array}$ & References \\
\hline Ireland coastline & WWIII & Deep-Water & Unstruct. & $2000-2013$ & $225 \mathrm{~m}$ & {$[111]$} \\
North Scotland (UK) & MIKE 21 & Spectral & Unstruct. & 2010 & $100 \mathrm{~m}$ & {$[112]$} \\
Brittany (France) & TOMAWAC & Spectral & Unstruct. & $2004-2011$ & $300 \mathrm{~m}$ & {$[113]$} \\
Sicily (Italy) & SWAN & Deep-Water & Unstruct. & $1995-2005$ & $228 \mathrm{~m}$ & {$[114]$} \\
Southeast Australia & SWAN & Spectral & Curvilinear & $1979-2010$ & $500 \mathrm{~m}$ & {$[115]$} \\
Irish West Coast & SWAN & Spectral & Unstruct. & $2005-2014$ & $85 \mathrm{~m}$ & {$[110]$} \\
Canada West Coast & SWAN & Spectral & Unstruct. & $2003-2014$ & $50 \mathrm{~m}$ & {$[19]$} \\
Eastern Ireland & SWAN & Deep-Water & Regular & $2004-2015$ & $300 \mathrm{~m}$ & {$[116]$} \\
\hline
\end{tabular}

\subsection{Refined Assessments}

\subsubsection{Wave and Tide Coupling}

Moreover the spatial and temporal resolutions, and the discretization in frequencies and directions, further uncertainties in numerical wave resource assessments may arise from the modelling setup including naturally the numerical approximations (solvers and schemes accuracies), but also (i) the type of boundary conditions, (ii) the method retained to compute wave power and (iii) the physical processes considered. Regarding the wave boundary conditions, the IEC recommends to rely on directional wave spectrum (extracted from regional embedded simulations) rather than exploiting predefined spectral shapes (such as JONSWAP or Pierson-Moscowitz) or hybrid spectrum based on parametric directional parameters. Indeed, as exhibited by Ramos and Ringwood [110], the type of boundary conditions may have a more significant impact than the grid resolution on resource assessment accuracy. Further differences may arise from the method retained to compute the available wave energy flux. Resource assessments based on SWAN compute thus the wave power density from the summation of squared energy transport components along eastern and northern directions, and this method neglects additional terms included when directly estimating the wave energy flux with the spectral formulation (Equation (1)) (as the squared of the summation is not equal to summation of the squared) [113]. In offshore waters of western Brittany (France), SWAN provided thus estimations of the mean wave power density 15\% lower than TOMAWAC (in which the spectral formulation was implemented). Following IEC, the most complete integration of physical processes impacting wave propagation must finally be considered. Particular attention must thus be dedicated to the balance between wave energy dissipations by whitecapping and bottom friction [117]. As many regions over the world, suitable for wave energy exploitation, experience large tidal ranges and associated strong tidal flows, special attention should also be paid to wave and current interactions. Indeed, tidal currents impact the wave propagation redistributing the overall energy in shallow water through a series of mechanisms (such as flattening/steepening, refraction, blocking or breaking mechanisms, etc.) which may result in variations of the wave energy flux of up to $60 \%$ in locations with strong tidal currents [118].

However, apart from a few investigations (Table 9), the tide-induced modulations were routinely ignored in numerical assessments of the wave energy resource (such as in the investigations listed in Tables 6-8). 
Table 9. Review of coastal numerical wave energy resource assessments which integrated the effects of tidal currents.

\begin{tabular}{|c|c|c|c|c|c|c|}
\hline $\begin{array}{l}\text { Application } \\
\text { Areas }\end{array}$ & $\begin{array}{l}\text { Wave } \\
\text { Models }\end{array}$ & $\begin{array}{c}\text { Tidal } \\
\text { Models }\end{array}$ & Coupling & Time Ranges & $\begin{array}{c}\text { Spatial Resol. } \\
\text { Reached }\end{array}$ & References \\
\hline NW European seas & SWAN & ROMS & One way & January 2005 & $0.04^{\circ}$ & [119] \\
\hline Gulf of Venice & SWAN & ROMS & Two way & January $2011 \rightarrow$ March 2011 & $500 \mathrm{~m}$ & [120] \\
\hline French Atlantic coast & WWIII & MARS 2D & One way & 1994-2012 & $200 \mathrm{~m}$ & [121] \\
\hline Orkney (Scotland) & SWAN & MOHID & One way & July $2006 \rightarrow$ August 2006 & $0.008^{\circ}$ & [118] \\
\hline Western Brittany & SWAN & Telemac 2D & One way & 2004-2011 & $300 \mathrm{~m}$ & [23] \\
\hline $\begin{array}{l}\text { Ushant-Molène } \\
\text { (western France) }\end{array}$ & SWAN & Telemac 2D & One way & November $2012 \rightarrow$ March 2013 & $50 \mathrm{~m}$ & [122] \\
\hline Coast of Japan & WWIII & JCOPE2 & One way & 1993-2014 & $1 \mathrm{~km}$ & [123] \\
\hline
\end{tabular}

One of the major explanation is associated with the computational resources required to perform these simulations. Indeed, current-induced refraction appears as one of the prominent mechanism leading to tide-induced wave modulations in coastal shelf seas with changes of the wave direction towards areas with lower propagation speed of the crest [89]. This influence is, most of the time, revealed in coastal wave buoys by observed semi-diurnal modulations of $H_{s}$ with variations liable to exceed $30 \%$ between the different phases of the tidal cycle [124]. A refined numerical approach of these large-scale effects requires therefore increased spatial resolutions liable to encompass the spatial variations of tidal current magnitudes and directions. As waves may also impact tidal currents through interaction of wave and current bottom boundary layers and/or the generation of wave-driven currents $[125,126]$, numerical simulations may furthermore involve two-way coupling where the wave and tidal circulation models exchange information at a regular time step. As these two constraints (spatial resolution and wave-tide coupling) increase the computational cost, resource assessments with tidal effects considered (i) simulation periods restricted to a couple of months and/or (ii) one-way coupling neglecting the effects of waves on tidal currents. However, despite these approximations, refined assessments of the wave energy resource were reached. By adopting a one-way coupling, Guillou [122] reproduced thus the modulations of the significant wave height and the wave direction observed at a wave buoy located in water depth of $60 \mathrm{~m}$ in western Brittany (Figure 6).
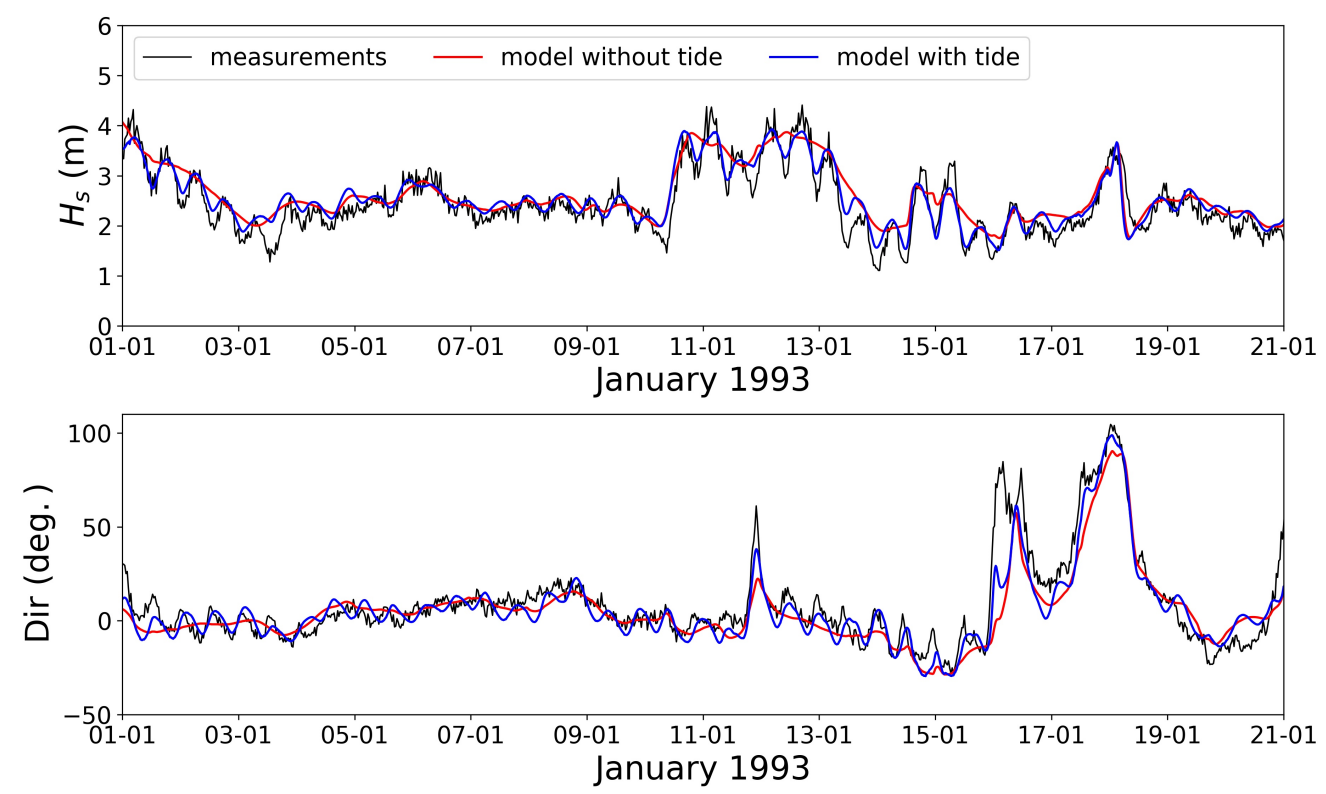

Figure 6. Measured (black line) and computed times series of the significant wave height $H_{S}$ and the mean wave direction (anticlockwise convention from the East) in January 2013 off western Brittany (France) (mean water depth of $60 \mathrm{~m}$ ) without (red line) and with (blue line) the effects of the tide-adapted from [122]. 
Despite being restricted to a limited period of time, the exploitation of the numerical simulations provided furthermore information about the influence of tidal currents on the available wave energy resource exhibiting increase of the available power over $100 \%$ in the entrance of the Fromveur Strait, a tidal stream energy site in western Brittany (Figure 7). Such significant variations were also obtained in the vicinity of the Pentland Firth (Orkney archipelago, north Scotland) with increase of the wave power density of up to $60 \%$ [118]. These investigations provided also further insights for a combined exploitation of tidal stream and wave energy in the vicinity of tidal stream energy sites. However, reduced variations were obtained in the most wave energetic sites located outside of these areas with strong tidal currents. The tide-induced modulations of the monthly averaged wave power were thus restricted to $10 \%$ in the exposed region of Ushant island (Figure 7). In the Gulf of Venice, Barbariol et al. [120] reported furthermore a decrease of the mean available wave power of up to $30 \%$ by integrating wave and current interactions. More recently, Webb et al. [123] exhibited the local and remote effects of oceanic currents along the coast of Japan revealing differences of up to $20 \%$. These large-scale effects suggested the integration of currents effects in wave energy resource assessments.
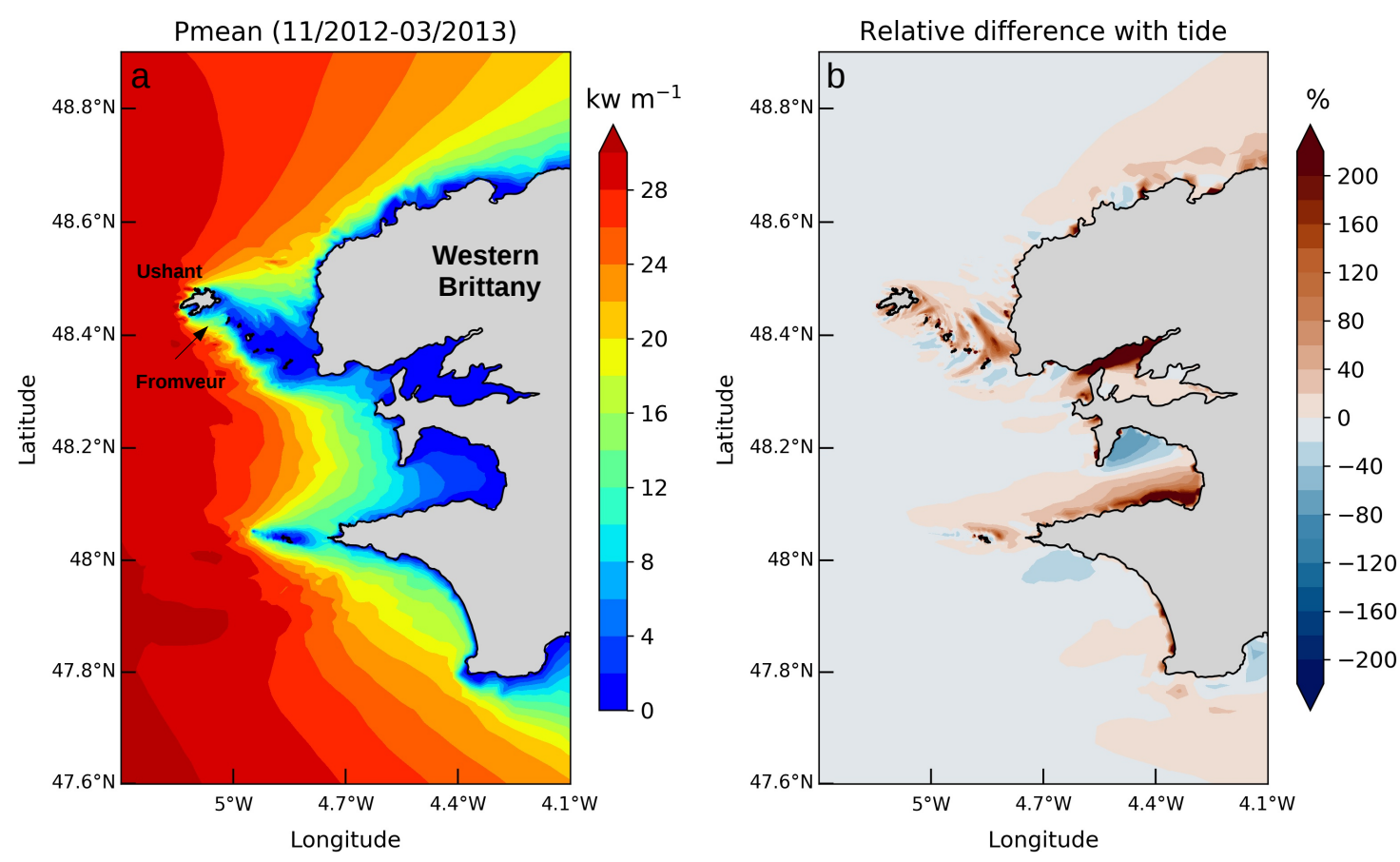

Figure 7. (a) Averaged wave power, in western Brittany (France), between November 2012 and March 2013 without tide and (b) relative differences (with respect to the configuration without tide) obtained with the inclusion of tide. Positive and negative values account for increase and reduction of predicted values with tide, respectively-adapted from [122].

\subsubsection{WEC Generated Power and Environmental Effects}

The expected generated power from WEC may show important differences with respect to the device technology. Numerous investigations were therefore conducted to assess WECs performance, and select and/or improve the technology for a given wave climate. The method combines WEC characteristics with observed or predicted time series of significant wave height and wave period ( $T_{p}$ or $T_{e}$ ) to compute the energy output. A generic method, independent from the device technology, was proposed by Portilla et al. [5] to optimize WEC installed capacity and rated power in locations characterized by contrasting wave climates. However, as it was difficult to associate results with a given technology, this method was applied in limited investigations [57]. The generated power was, most of the time, approached by combining wave scatter diagrams with WECs power matrices 
(Equation (6), Section 2.2.2). Although local investigations were conducted by relying on high-temporal observations at wave buoys e.g., [127,128], WECs performance were mainly assessed by exploiting hindcast simulations to extend the temporal and spatial scales of the analysis (see [6] for a review). The different investigations provided estimations of the mean and averaged generated powers, capacity factor, and the percentage of the time the device was producing energy. Besides the identification of the areas with the highest generated power, particular attention was dedicated to the annual and seasonal variabilities in WECs performance e.g., [6,31,129]. Indeed, whereas the available resource may show important temporal variabilities (particularly noticeable in the most energetic locations), the generated power was characterized by smoothed temporal variations liable to reduce intermittency in the energy output between the winter and the summer periods [6]. These effects may be beneficial to the energy production, but are also associated with reduced devices performance. By exploiting a 58-years hindcast simulation along the French Atlantic coast, Sierra et al. [31] obtained thus averaged capacity factors below $17 \%$ for the Pelamis device. In offshore waters of western Brittany, Guillou and Chapalain [6] confirmed such values for Pelamis (with averaged CF between 12 and $16 \%$ ) and AquabuOY (with averaged CF between 14 and $18 \%$ ) by exploiting a 8-years hindcast database. However, these different estimations depend naturally on the temporal variability of the wave climate, which itself depends on (i) the period covered by resource assessment and (ii) the location considered. In offshore waters of northern Galicia (Spain), Carballo et al. [129] obtained thus monthly averaged values of CF liable to exceed 35\% during the winter period for Pelamis and AquaBuOY. This variability of the capacity factor was confirmed by Guillou and Chapalain [6] at three offshore locations in western Brittany (Figure 8). These results exhibited furthermore significant temporal variations of the monthly averaged $\mathrm{CF}$ with respect to the year considered for resource assessment.
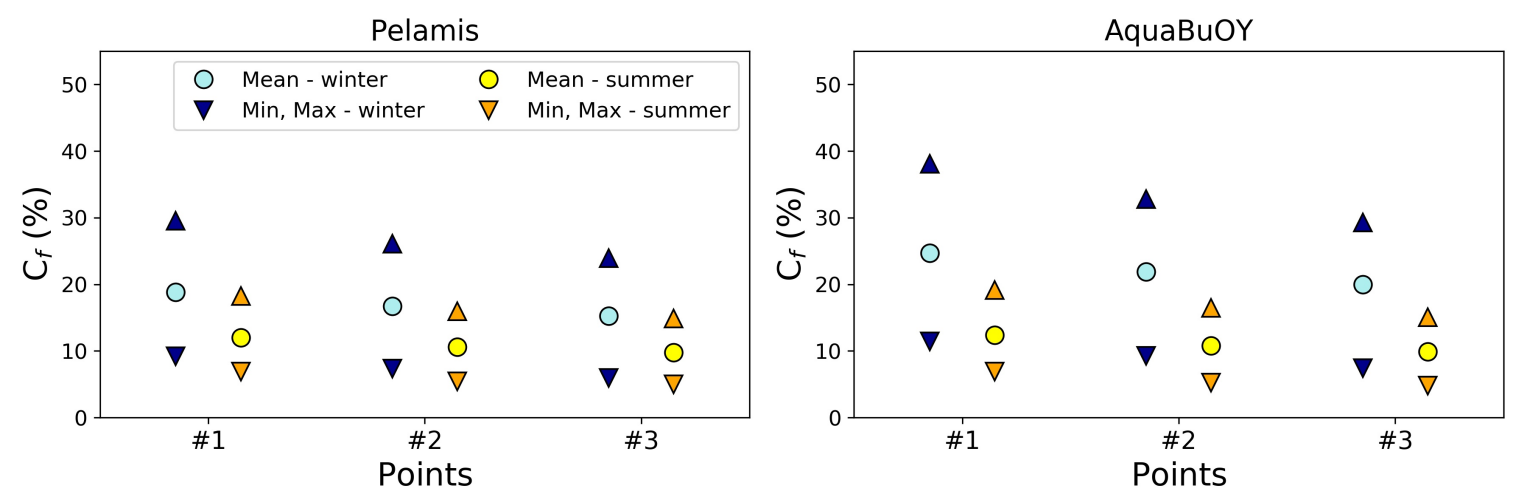

Figure 8. Mean, maximum and minimum monthly averaged capacity factors CF in winter (December-January-February) and summer (June-July-August) periods between 2004 and 2011 for Pelamis and AquaBuOY devices at three locations in offshore waters (between 50 and $70 \mathrm{~m}$ ) of western Brittany (France) adapted from [6].

By extracting energy from the marine environment, WEC may also alter the wave conditions, the available resource and the generated power. Resource assessment at the scale of a wave farm project may therefore require a detailed approach of the interaction between waves and energy converters. However, baseline versions of state-of-the-art phase-averaged wave models do not have the capabilities to simulate WEC effects. The basic approach consists of representing WEC as an obstacle with a constant transmission coefficient across the whole incident wave spectrum to determine the amount of wave energy absorbed. Refined approaches were also proposed based on (i) evaluations of transmission coefficients in laboratory studies [130], frequency-dependent wave energy transmission [131], or obstacle transmission specified based on device-specific WEC characteristics [132]. As these investigations required highly refined spatial resolutions matching the size of WEC devices (typically several meters), stationary simulations were conducted focusing on the spatial changes of a wave field for given incident conditions in terms of wave height, period 
and direction. Results obtained exhibited a decrease of the significant wave height between the projected wave farm and the coastline, which evolved nearly linearly with the increase of the wave energy transmission [133]. And this resulted in a series of simulations applied to approach the far-field environmental effects of energy converters focusing especially on the modifications of nearshore wave conditions behind the wave farm rather than assessing modifications on the generated power e.g., [131-135].

\section{Conclusions}

The present investigation complements the latest technical specifications to assess the wave energy resource by providing an up-to-date review of the recent studies conducted at shelf, regional and coastal scales. An overall description of formulations and methods adopted to compute the wave energy flux and generated power is provided with an extensive review of metrics and selection indexes considered to refine the analysis. Resource assessments clearly depend on the available data and the objective considered. The main outcomes of the present review are as follows:

1 In situ observations are accurate representations of the wave conditions in the marine environment. However, these data are rarely available in locations retained for wave energy exploitation generally characterized by severe storm energetic conditions with reduced lifespan of the instrumentation systems. Measurements cover furthermore restricted period of time with a series of gap in the recorded data. Wave resource assessments based on in situ measurements were thus mainly conducted in areas with a high density of wave stations such as the NDBC network off the West and East Coasts of the USA. In spite of these limitations, in situ observations represent valuable data to characterize the uncertainties in wave power formulations providing further insights about the calibration coefficients between the energy period and the peak or the mean periods (traditionally available in hindcast databases).

2 Despite important spatial and temporal limitations, satellite observations may complement, in offshore waters, the local resource assessments based on in situ measurements. The investigations exploited combinations of multi-satellite altimeters to characterize, over decades, the spatial distribution of energetic spots and provide information about the resource temporal variability. However, the exploitation requires inversion models to estimate the wave period with further assumption of the energy period considered to estimate the wave power density in offshore waters.

3 The exploitation of available numerical hindcast databases and reanalysis archives is an alternative to time-consuming simulations that require complex model implementations, long-term computations, refined assessments and treatments of predictions. In comparison with observations, these data represent long-term time series that continuously capture the evolution of the wave condition. However, due to limited storage space, the recorded sea wave characteristics (at the different computational grid nodes) were restricted to integrated parameters such as the significant wave height $H_{s}$ or statistical periods (e.g., $T_{p}, T_{m}$ ) setting aside a detailed assessment of the wave energy spectrum and the associated available wave energy flux. Resource assessments were thus conducted by relying on simplified formulations of the wave power density restricted to offshore waters.

4 By computing the evolution of the wave energy spectrum in spatial, frequency and directional spaces, numerical simulations provided a direct access to the wave energy density based on the spectral formulation. The latest development of computational resources and phase-averaged models implemented in unstructured computational grids enable the conducting of hindcast simulations at the scale of a wave farm with refined spatial resolutions of the order of several tens of meters. However, further uncertainties in wave resource assessments may arise from the interaction with a tidal current liable to induce variations of up to $60 \%$ of the available wave energy flux. It is thus suggested to include these effects to refine the numerical assessments of the wave energy resource in areas with large tidal ranges. 
5 The assessment of the power generated by WEC is also an important stage to evaluate or adapt the performances of devices while refining the location targeted for their implementations. As state-of-the-art phase-averaged models used to assess the available resource are not adapted to represent the complex hydrodynamic interactions with WEC, the generated power is estimated, with a simple approach, by combining wave scatter diagrams with devices power matrices. These investigations exploited long-term simulations of the wave climate exhibiting the filter effects that devices may have on the temporal variability of the generated power. Despite being beneficial to reducing the intermittency of energy production and facilitating its integration into the grid, this results also to reduced performance with weak values of the capacity factors in comparison with other technologies such as tidal stream turbines.

An accurate identification of a wave energy site and selection of WEC technologies is thus a cumbersome process which requires an access to a significant amount of data characterizing the evolution of the wave energy spectrum over a period long enough to represent the temporal variability of the wave conditions. This review exhibits the methods currently implemented to assess the available wave energy resource and expected generated power at the different stages of a wave energy project (such as reconnaissance, feasibility and design). Numerical reliable simulations, assessed against in situ and satellite observations in the area of interest, have the potential to provide noticeable information. However, following the technical specifications of IEC, it is suggested to cover at least ten years. This period must be the most recent given the potential evolution of waves conditions with climate change. At the scale of a wave farm, the spatial resolution should furthermore be increased to approach the modulations induced by wave-current interactions and the effects of a series of energy converters. These temporal and spatial specifications require high computational resources. Nevertheless, the development of numerical and IT resources may help to approach, with reduced uncertainties, the long-term variabilities of the wave climate, and provide an assessment of the future performance of WEC in the marine environment.

Author Contributions: N.G.: Conceptualization, Formal analysis, Writing-Original Draft, Writing-Review \& Editing, Visualization, Supervision, Project administration. G.L.: Conceptualization, Writing-Original Draft, Writing-Review \& Editing. G.C.: Writing-Review \& Editing. All authors have read and agreed to the published version of the manuscript.

Funding: This research received no external funding.

Acknowledgments: The present paper is a contribution to the research program DIADEME ("Design et InterActions des Dispositifs d'extraction d'Energies Marines avec l'Environnement") of the Laboratory of Coastal Engineering and Environment (Cerema, http:/ / www.cerema.fr).

Conflicts of Interest: The authors declare no conflict of interest.

\section{References}

1. Gunn, K.; Stock-Williams, C. Quantifying the global wave power resource. Renew. Energy 2012, 44, $296-304$. [CrossRef]

2. Reguero, B.; Losada, I.J.; Mendez, J.F. A recent increase in global wave power as a consequence of oceanic warming. Nat. Commun. 2019. [CrossRef]

3. Friedrich, D.; Lavidas, G. Evaluation of the effect of flexible demand and wave energy converters on the design of Hybrid Energy Systems. Renew. Power Gener. 2017, 12. [CrossRef]

4. De O Falcão, A.F. Wave energy utilization: A review of the technologies. Renew. Sustain. Energy Rev. 2010, 14, 899-918. [CrossRef]

5. Portilla, J.; Sosa, J.; Cavaleri, L. Wave energy resources: Wave climate and exploitation. Renew. Energy 2013, 57, 594-605. [CrossRef]

6. Guillou, N.; Chapalain, G. Annual and seasonal variabilities in the performances of wave energy converters. Energy 2018, 165, 812-823. [CrossRef]

7. TheStartup. Wave Power Might Be Feasible After All. 2020. Available online: https://medium.com/swlh/ wave-power-might-be-feasible-after-all-a2957622b6d (accessed on 13 May 2020). 
8. Henderson, R. Design, simulation, and testing of a novel hydraulic power take-off system for the Pelamis wave energy converter. Renew. Energy 2006, 31, 271-283. [CrossRef]

9. Eco Wave Power. Available online: https://www.ecowavepower.com/future-projects/ (accessed on 7 September 2020).

10. Power Buoy Device, Ocean Power Technology. Available online: https:/ / oceanpowertechnologies.com/ pb3-powerbuoy/ (accessed on 7 September 2020).

11. EMEC. Assessment of Wave Energy Resource-Marine Renewable Energy Guides; Technical Report; The European Marine Energy Centre Ltd.: Stromness, UK, 2009.

12. Mackay, E.B.L. Resource Assessment for Wave Energy. In Comprehensive Renewable Energy; Sayigh, A., Ed.; Elsevier: Oxford, UK, 2012; Volume 8, pp. 11-77.

13. Folley, M.; Cornett, A.; Holmes, B.; Lenee-Bluhm, P.; Liria, P. Standardising resource assessment for wave energy converters. In Proceedings of the ICOE 2012, Dublin, Ireland, 17-19 October 2012.

14. Ingram, D.; Smith, G.H.; Ferriera, C.; Smith, H. Protocols for the Equitable Assessment of Marine Energy Converters; Technical Report; Institute of Energy Systems, University of Edinburgh, School of Engineering: Edinburgh, UK, 2011.

15. IEC. Wave Energy Resource Assessment and Characterization; Technical Report 62600-101; International Electrotechnical Commission/Technical Section: Geneva, Switzerland, 2014.

16. Ramos, V.; Carballo, R.; Ringwood, J. Assessing the utility and effectiveness of the IEC standards for wave energy resource characterisation. In Progress in Renewable Energies Offshore; Soares, G., Ed.; Taylor \& Francis: London, UK, 2016.

17. Cornett, A.; Toupin, M.; Baker, S.; Piche, S.; Nistor, I. Appraisal of IEC Standards for Wave and Tidal Energy Resource Assessment. In Proceedings of the ICOE 2014, Halifax, NS, Canada, 4-6 November 2014.

18. Piche, S.; Cornett, A.; Baker, S.; Nistor, I. Validation of the IEC Technical Specification for Wave Energy Resource Assessment. In Proceedings of the 11th European Wave and Tidal Energy Conference, Nantes, France, 6-11 September 2015.

19. Robertson, B.; Hiles, C.; Luczko, E.; Buckham, B. Quantifying wave power and wave energy converter array production potential. Int. J. Mar. Energy 2016, 14, 143-160. [CrossRef]

20. Lavidas, G.; Venugopal, V. Application of numerical wave models at European coastlines: A review. Renew. Sustain. Energy Rev. 2018, 92, 489-500. [CrossRef]

21. Guillou, N. Estimating wave energy flux from significant wave height and peak period. Renew. Energy 2020, 155, 1383-1393. [CrossRef]

22. Robertson, B. Wave Energy Assessments: Quantifying the Resource and Understanding the Uncertainty. In Marine Renewable Energy—Resource Characterization and Physical Effects; Yang, Z., Copping, A., Eds.; Springer: Berlin/Heidelberg, Germany, 2017.

23. Guillou, N.; Chapalain, G. Numerical modelling of nearshore wave energy resource in the Sea of Iroise. Renew. Energy 2015, 83, 942-953. [CrossRef]

24. Lavidas, G. Selection index for Wave Energy Deployments (SIWED): A near-deterministic index for wave energy converters. Energy 2020, 196, 117131. [CrossRef]

25. Schmitt, P.; Elsäßer, B. The application of Froude scaling to model tests of Oscillating Wave Surge Converters. Ocean Eng. 2017, 141, 108-115. [CrossRef]

26. Kamranzad, B.; Etemad-Shahidi, A.; Chegini, V.; Yeganeh-Bakhtiary, A. Climate change impact on wave energy in the Persian Gulf. Ocean Dyn. 2015, 65, 777-794. [CrossRef]

27. Kamranzad, B.; Lavidas, G.; Takara, K. Spatio-Temporal Assessment of Climate Change Impact on Wave Energy Resources Using Various Time Dependent Criteria. Energies 2020, 13, 768. [CrossRef]

28. Wan, Y.; Zhang, J.; Meng, J.; Wang, J. A wave energy resource assessment in the China's seas based on multi-satellite merged radar altimeter data. Acta Oceanol. Sin. 2015, 34, 115-124. [CrossRef]

29. Cornett, A. A global wave energy resource assessment. In Proceedings of the 18th International Offshore and Polar Engineering Conference, Vancouver, BC, Canada, 6-11 July 2008.

30. Pastor, J.; Liu, Y. Wave Climate Resource Analysis Based on a Revised Gamma Spectrum for Wave Energy Conversion Technology. Sustainability 2016, 8, 1321. [CrossRef]

31. Sierra, J.P.; White, A.; Mösso, C.; Mestres, M. Assessment of the intra-annual and inter-annual variability of the wave energy resource in the Bay of Biscay (France). Energy 2017, 141, 853-868. [CrossRef] 
32. Arena, F.; Laface, V.; Malara, G.; Romolo, A.; Viviano, A.; Fiamma, V.; Sannino, G.; Carillo, A. Wave climate analysis for the design of wave energy harvesters in the Mediterranean Sea. Renew. Energy 2015, 77, 125-141. [CrossRef]

33. Sheng, W.; Li, H. A Method for Energy and Resource Assessment of Waves in Finite Water Depths. Energies 2017, 10, 640 .

34. Ahn, S.; Haas, K.A.; Neary, V.S. Wave energy resource classification system for US coastal waters. Renew. Sustain. Energy Rev. 2019, 104, 54-68. [CrossRef]

35. Gonçalves, M.; Martinho, P.; Guedes Soares, C. A 33-year hindcast on wave energy assessment in the western French coast. Energy 2018, 165, 790-801. [CrossRef]

36. Babarit, A. A database of capture width ratio of wave energy converters. Renew. Energy 2015, 80, 610-628. [CrossRef]

37. Bozzi, S.; Miquel, A.M.; Antonini, A.; Passoni, G.; Archetti, R. Modeling of a point absorber for energy conversion in Italian seas. Energies 2013, 6, 3033-3051. [CrossRef]

38. de Andres, A.; Guanche, R.; Vidal, C.; Losada, I. Adaptability of a generic wave energy converter to different climate conditions. Renew. Energy 2015, 78, 322-333. [CrossRef]

39. Rusu, E.; Onea, F. A review of the technologies for wave energy extraction. Clean Energy 2018, 1-10. [CrossRef]

40. Babarit, A.; Hals, J.; Muliawan, M.; Kurniawan, A.; Moan, T.; Krokstad, J. Numerical benchmarking study of a selection of wave energy converters. Renew. Energy 2012, 41, 44-63. [CrossRef]

41. Day, A.; Babarit, A.; Fontaine, A.; He, Y.P.; Kraskowski, M.; Murai, M.; Penesis, I.; Salvatore, F.; Shin, H.K. Hydrodynamic modelling of marine renewable energy devices: A state of the art review. Ocean Eng. 2015, 108, 46-69. [CrossRef]

42. Rusu, E.; Onea, F. Estimation of the wave energy conversion efficiency in the Atlantic Ocean close to the European islands. Renew. Energy 2016, 85, 687-703. [CrossRef]

43. Lavidas, G.; Agarwal, A.; Venugopal, V. Availability and Accessibility for Offshore Operations in the Mediterranean Sea. J. Waterw. Port Coastal Ocean Eng. 2018, 144, 1-13. [CrossRef]

44. Dalton, G.J.; Alcorn, R.; Lewis, T. Case study feasibility analysis of the Pelamis wave energy convertor in Ireland, Portugal and North America. Renew. Energy 2010, 35, 443-455. [CrossRef]

45. Andrés, A.D.; Macgillivray, A.; Guanche, R.; Jeffrey, H. Factors affecting LCOE of Ocean energy technologies: A study of technology and deployment attractiveness. In Proceedings of the 5th International Conference on Ocean Energy, Halifax, NS, Canada, 4-6 November 2014; pp. 1-11.

46. Lavidas, G.; Venugopal, V. Wave energy resource evaluation and characterisation for the Libyan Sea. Int. J. Mar. Energy 2017, 18. [CrossRef]

47. Simal, P.D.; Ortega, S.T.; Bas, B.; Elginoz, N.; Garcia, R.G.; Jesus, F.; Giannakis, E.; Giannouli, A.; Koundouri, P.; Moussoulides, A.; et al. Socio-economic Assessment of a Selected Multi-use Offshore Site in the Atlantic. In The Ocean of Tomorrow; Koundouri, P., Ed.; Springer International Publishing AG: Berlin/Heidelberg, Germany, 2017. [CrossRef]

48. Hagerman, G. Southern New England Wave Energy Resource Potential. In Proceedings of the Building Energy, Boston, MA, USA, 21-24 March 2001.

49. Akpinar, A.; İhsan Kömürcü, M. Wave energy potential along the south-east coasts of the Black Sea. Energy 2012, 42, 289-302. [CrossRef]

50. Lavidas, G.; Venugopal, V.; Friedrich, D. Wave energy extraction in Scotland through an improved nearshore wave atlas. Int. J. Mar. Energy 2017, 17, 64-83. [CrossRef]

51. Kamranzad, B.; Etemad-Shahidi, A.; Chegini, V. Developing an optimum hotspot identifier for wave energy extracting in the northern Persian Gulf. Renew. Energy 2017, 114, 59-71. [CrossRef]

52. Ahn, S.; Haas, K.A.; Neary, V.S. Wave energy resource characterization and assessment for coastal waters of the United States. Appl. Energy 2020, 267, 114922. [CrossRef]

53. Kamranzad, B.; Hadadpour, S. A multi-criteria approach for selection of wave energy converter/location. Energy 2020, 204, 117924. [CrossRef]

54. Budar, K.; Falnes, G. A resonant point absorber of ocean-wave power. Nature 1975, 256, 478-479. [CrossRef]

55. Defne, Z.; Haas, K.A.; Fritz, H.M. Wave power potential along the Atlantic coast of the southeastern USA. Renew. Energy 2009, 34, 2197-2205. [CrossRef] 
56. Ozkan, C.; Mayo, T. The renewable wave energy resource in coastal regions of the Florida peninsula. Renew. Energy 2019, 139, 530-537. [CrossRef]

57. Guillou, N.; Chapalain, G. Assessment of wave power variability and exploitation with a long-term hindcast database. Renew. Energy 2020, 154, 1272-1282. [CrossRef]

58. Wu, S.; Liu, C.; Chen, X. Offshore wave energy resource assessment in the East China Sea. Renew. Energy 2015, 76, 628-636. [CrossRef]

59. Mackay, E.; Bahaj, A.; Retzler, C.; Challenor, P. Wave energy resource assessment using satellite altimeter data. In Proceedings of the ASME 27th International Conference on Offshore Mechanics and Arctic Engineering, Estoril, Portugal, 15-20 June 2008.

60. Pontes, M.; Bruck, M.; Lehner, S. Assessing the wave energy resource using remote sensed data. In Proceedings of the 8th European Wave and Tidal Energy Conference, Uppsala, Sweden, 7-10 September 2009; pp. 111-116.

61. Neill, S.; Hashemi, M. Fundamentals of Ocean Renewable Energy-Generating Electricity from the Sea; Elsevier Academic Press: London, UK, 2018.

62. Krogstad, H.E.; Barstow, S.F. Satellite Wave Measurements for Coastal Engineering Applications. Coast. Eng. 1999, 37, 283-307. [CrossRef]

63. Queffeulou, P.; Bentamy, A.; Croizé-Fillon, D. Validation Status of a Global Altimeter Wind \& Wave Data Base. In Proceedings of the OSTST 2010 Meeting, Lisbon, Portugal, 18-22 October 2010.

64. Davies, C.G.; Cottom, P.D.; Chalenor, P.G.; Carter, D.J. On the Measurements of Wave Period from Radar Altimeters, Ocean Wave Measurements and Analysis. In Proceedings of the 3rd International Symposium Waves'97, Virginia Beach, Virginia, 3-7 November 1997

65. Gommenginger, C.P.; Sroksoz, M.A.; Challenor, P.G. Measuring ocean wave period with satellite altimeters: A simple empirical model. Geophys. Res. Lett. 2003, 30. [CrossRef]

66. Quilfen, Y.; Chapron, B.; Collard, F.; Serre, M. Calibration/validation of an altimeter wave period model and application to TOPEX/Poseidon and Jason-1 altimeters. Mar. Geod. 2004, 27, 535-549. [CrossRef]

67. Quilfen, Y.; Chapron, B.; Collard, F.; Serre, M. A parametric model for ocean wave period from Ku band altimeter. J. Geophys. Res. 2008, 113. [CrossRef]

68. Yaakob, O.; Hashim, F.E.; Omar, K.M.; Din, A.H.M.; Koh, K.K. Satellite-based wave data and wave energy resource assessment for South China Sea. Renew. Energy 2016, 88, 359-371. [CrossRef]

69. Dobson, E.; Monaldo, F.; Goldhirsh, J.; Wilkerson, J. Validation of Geostat altimeter-derived wind speeds and significant wave heights using buoy data. J. Geophys. Res. Ocean. 1987, 92. [CrossRef]

70. Monaldo, F. Expected differences between buoy and radar altimeter estimates of wind speed and significant wave height and their implications on buoy-altimeter comparisons. J. Geophys. Res. 1988, 93, 2285-2302. [CrossRef]

71. Goddijn-Murphy, L.; Míguez, B.M.; McIlvenny, J.; Gleizon, P. Wave energy resource assessment with Altika satellite altimetry: A case study at a wave energy site. Geophys. Res. Lett. 2015, 42, 5452-5459. [CrossRef]

72. Ribal, A.; Zieger, S. Wave Energy Resource Assessment Based on Satellite Observations around Indonesia. In Proceedings of the 3rd AUN/SEED-NET Regional Conference on Energy Engineering and the 7th International Conference on Thermofluids, Yogyakarta, Indonesia, 19-20 November 2015.

73. Ribal, A.; Thamrin, S.A. A 10-year wave energy resource assessment and trends of Indonesia based on satellite observations. Acta Oceanol. Sin. 2019, 38, 86-93.

74. Wan, Y.; Zhang, J.; Meng, J.; Wang, J.; Dai, Y. Study on wave energy resource assessing method based on altimeter data-A case study in Northwest Pacific. Acta Oceanol. Sin. 2016, 35, 117-129. [CrossRef]

75. Reguero, B.; Losada, I.; Méndez, F. A global wave power resource and its seasonal, interannual and long-term variability. Appl. Energy 2015, 148, 366-380. [CrossRef]

76. Pilar, P.; Soares, C.G.; Carretero, J. 44-year wave hindcast for the North East Atlantic European coast. Coast. Eng. 2008, 55, 861-871. [CrossRef]

77. Sierra, J.; González-Marco, D.; Sospedra, J.; Gironella, X.; Mösso, C.; Sánchez-Arcilla, A. Wave energy resource assessment in Lanzarote (Spain). Renew. Energy 2013, 55, 480-489. [CrossRef]

78. Durrant, T.; Greenslade, D.; Hemer, M.; Trenham, C. A Global Hindcast Focussed on the Central and South Pacific; Technical Report 70, CAWCR Technical Report; CSIRO and the Bureau of Meteorology: Canberra, Australia. 2014. 
79. Hemer, M.A.; Zieger, S.; Durrant, T.; O'Grady, J.; Hoeke, R.K.; McInnes, K.L.; Rosebrock, U. A revised assessment of Australia's national wave energy resource. Renew. Energy 2017, 114, 85-107. [CrossRef]

80. Reguero, B.G.; Menéndez, M.; Méndez, F.J.; Mínguez, R.; Losada, I.J. A Global Ocean Wave (GOW) calibrated reanalysis from 1948 onwards. Coast. Eng. 2012, 65, 38-55. [CrossRef]

81. Dee, D.; Uppala, S.; Simmons, A.; Berrisford, P.; Poli, P.; Kobayashi, S.; Andrae, U.; Alonso-Balmaseda, M.; Balsamo, G.; Bauer, P.; et al. The ERA-Interim reanalysis: Configuration and performance of the data assimilation system-This report is superseded by the version. Q. J. R. Meteorol. Soc. 2011, 137, 553-597. [CrossRef]

82. Sanil Kumar, V.; Anoop, T.R. Wave energy resource assessment for the Indian shelf seas. Renew. Energy 2015, 76, 212-219. [CrossRef]

83. National Centers for Environmental Prediction-National Oceanographic and Atmospheric Administration. WAVEWATCH III 30-year Hindcast Phase 2. Available online: https:/ / polar.ncep.noaa.gov/waves / hindcasts/nopp-phase2.php (accessed on 10 June 2020).

84. Marine Modeling and Analysis Branch-National Oceanographic and Atmospheric Administration. Available online: https:/ / polar.ncep.noaa.gov / waves/implementations.php (accessed on 10 June 2020).

85. Hughes, M.G.; Heap, A.D. National-scale wave energy resource assessment for Australia. Renew. Energy 2010, 35, 1783-1791. [CrossRef]

86. Sierra, J.; Mösso, C.; González-Marco, D. Wave energy resource assessment in Menorca (Spain). Renew. Energy 2014, 71, 51-60. [CrossRef]

87. The Wamdi Group. The WAM Model-A Third Generation Ocean Wave Prediction Model. J. Phys. Oceanogr. 1988, 18, 1775-1810. [CrossRef]

88. Tolman, H.L. A Third-Generation Model for Wind Waves on Slowly Varying, Unsteady, and Inhomogeneous Depths and Currents. J. Phys. Oceanogr. 1991, 21, 782-797. [CrossRef]

89. Holthuijsen, L. Waves in Oceanic and Coastal Waters; Cambridge University Press: Cambridge, UK, 2007; p. 387.

90. Neill, S.P.; Hashemi, M.R. Wave power variability over the northwest European shelf seas. Appl. Energy 2013, 106, 31-46. [CrossRef]

91. Wang, Z.; Duan, C.; Dong, S. Long-term wind and wave energy resource assessment in the South China sea based on 30-year hindcast data. Ocean Eng. 2018, 163, 58-75. [CrossRef]

92. Pontes, M.T.; Athanassoulis, G.A.; Barstow, S.; Cavaleri, L.; Holmes, B.; Mollison, D.; Oliveira-Pires, H. An Atlas of the Wave-Energy Resource in Europe. J. Offshore Mech. Arct. Eng. 1996, 118, 307. [CrossRef]

93. Besio, G.; Mentaschi, L.; Mazzino, A. Wave energy resource assessment in the Mediterranean Sea on the basis of a 35-year hindcast. Energy 2016, 94, 50-63. [CrossRef]

94. Aboobacker, V.; Shanas, P.; Alsaafani, M.; Albarakati, A.M. Wave energy resource assessment for Red Sea. Renew. Energy 2017, 114, 46-58. [CrossRef]

95. Ribal, A.; Babanin, A.V.; Zieger, S.; Liu, Q. A high-resolution wave energy resource assessment of Indonesia. Renew. Energy 2020. [CrossRef]

96. SWAN team SWAN Cycle III. Version 41.01 AB-Scientific and Technical Documentation; Technical Report; Delft University of Technology: Delft, The Netherlands, 2015.

97. Amarouche, K.; Akpinar, A.; Bachari, N.E.I.; Houma, F. Wave energy resource assessment along the Algerian coast based on 39-year wave hindcast. Renew. Energy 2020, 153, 840-860. [CrossRef]

98. Saket, A.; Etemad-Shahidi, A. Wave energy potential along the northern coasts of the Gulf of Oman, Iran. Renew. Energy 2012, 40, 90-97. [CrossRef]

99. Alonso, R.; Jackson, M.; Santoro, P.; Fossati, M.; Solari, S.; Teixeira, L. Wave and tidal energy resource assessment in Uruguayan shelf seas. Renew. Energy 2017, 114, 18-31. [CrossRef]

100. Lavidas, G.; Polinder, H. North Sea Wave Database (NSWD) and the Need for Reliable Resource Data: A 38 Year Database for Metocean and Wave Energy Assessments. Atmosphere 2019, 10, 551. [CrossRef]

101. Akpınar, A.; İhsan Kömürcü, M. Assessment of wave energy resource of the Black Sea based on 15-year numerical hindcast data. Appl. Energy 2013, 101, 502-512. [CrossRef]

102. Kamranzad, B.; Etemad-shahidi, A.; Chegini, V. Assessment of wave energy variation in the Persian Gulf. Ocean Eng. 2013, 70, 72-80. [CrossRef]

103. Rusu, E.; Onea, F. Evaluation of the wind and wave energy along the Caspian Sea. Energy 2013, 50, 1-14. [CrossRef] 
104. Gonçalves, M.; Martinho, P.; Soares, C.G. Wave energy conditions in the western French coast. Renew. Energy 2014, 62, 155-163. [CrossRef]

105. Lavidas, G.; Venugopal, V. A 35 year high-resolution wave atlas for nearshore energy production and economics at the Aegean Sea. Renew. Energy 2017, 103, 401-417. [CrossRef]

106. Lavidas, G.; Venugopal, V. Prospects and applicability of wave energy for South Africa. Int. J. Sustain. Energy 2018, 37, 230-248. [CrossRef]

107. Eum, H.S.; Jeong, W.M.; Chang, Y.S.; Oh, S.H.; Park, J.J. Wave Energy in Korean Seas from 12-Year Wave Hindcasting. J. Mar. Sci. Eng. 2020, 8, 161. [CrossRef]

108. DHI MIKE 21. Available online: http://www.mikebydhi.com/products/mike-21 (accessed on 7 September 2020).

109. EDF R\&D. TOMAWAC—Software for Sea State Modelling on Unstructured Grids over Oceans and Coastal Seas; Technical Report; EDF: Paris, France, 2011.

110. Ramos, V.; Ringwood, J.V. Exploring the utility and effectiveness of the IEC (International Electrotechnical Commission) wave energy resource assessment and characterisation standard: A case study. Energy 2016, 107, 668-682. [CrossRef]

111. Gallagher, S.; Tiron, R.; Whelan, E.; Gleeson, E.; Dias, F.; McGrath, R. The nearshore wind and wave energy potential of Ireland: A high resolution assessment of availability and accessibility. Renew. Energy 2016, 88, 494-516. [CrossRef]

112. Venugopal, V.; Nemalidinne, R. Wave resource assessment for Scottish waters using a large scale North Atlantic spectral wave model. Renew. Energy 2015, 76, 503-525. [CrossRef]

113. Guillou, N. Evaluation of wave energy potential in the Sea of Iroise with two spectral models. Ocean Eng. 2015, 106, 141-151. [CrossRef]

114. Monteforte, M.; Re, C.L.; Ferreri, G. Wave energy assessment in Sicily (Italy). Renew. Energy 2015, 78, $276-287$. [CrossRef]

115. Morim, J.; Cartwright, N.; Etemad-Shahidi, A.; Strauss, D.; Hemer, M. Wave energy resource assessment along the Southeast coast of Australia on the basis of a 31-year hindcast. Appl. Energy 2016, 184, $276-297$. [CrossRef]

116. Atan, R.; Goggins, J.; Nash, S. Galway Bay-The 1/4 scale wave energy test site? A detailed wave energy resource assessment and investigation of scaling factors. Renew. Energy 2018, 119, 217-234. [CrossRef]

117. Guillou, N. Wave-energy dissipation by bottom friction in the English Channel. Ocean Eng. 2014, 82, 42-51. [CrossRef]

118. Saruwatari, A.; Ingram, D.M.; Cradden, L. Wave-current interaction effects on marine energy converters. Ocean Eng. 2013, 73, 106-118. [CrossRef]

119. Hashemi, M.R.; Neill, S.P. The role of tides in shelf-scale simulations of the wave energy resource. Renew. Energy 2014, 69, 300-310. [CrossRef]

120. Barbariol, F.; Benetazzo, A.; Carniel, S.; Sclavo, M. Improving the assessment of wave energy resources by means of coupled wave-ocean numerical modeling. Renew. Energy 2013, 60, 462-471. [CrossRef]

121. Boudière, E.; Maisondieu, C.; Ardhuin, F.; Accensi, M.; Pineau-Guillou, L.; Lepesqueur, J. A suitable metocean hindcast database for the design of Marine Energy Converters. Int. J. Mar. Energy 2013, 3-4, e40-e52. [CrossRef]

122. Guillou, N. Modelling effects of tidal currents on waves at a tidal stream energy site. Renew. Energy 2017, 114, 180-190. [CrossRef]

123. Webb, A.; Waseda, T.; Kiyomatsu, K. A high-resolution, long-term wave resource assessment of Japan with wave-current effects. Renew. Energy 2020. [CrossRef]

124. Guillou, N.; Chapalain, G. Modeling the tide-induced modulation of wave height in the outer Seine estuary. J. Coast. Res. 2012, 28, 613-623.

125. Guillou, N.; Chapalain, G. Modelling impact of northerly wind-generated waves on sediments resuspensions in the Dover Strait and adjacent waters. Cont. Shelf Res. 2011, 31, 1894-1903. [CrossRef]

126. Guillou, N.; Chapalain, G.; Neill, S.P. The influence of waves on the tidal kinetic energy resource at a tidal stream energy site. Appl. Energy 2016, 180, 402-415. [CrossRef]

127. Cahill, B.; Lewis, T. Wave energy resource characterisation of the Atlantic Marine Energy Test Site. Int. J. Mar. Energy 2013, 1, 3-15. [CrossRef]

128. Bozzi, S.; Archetti, R.; Passoni, G. Wave electricity production in Italian offshore: A preliminary investigation. Renew. Energy 2014, 62, 407-416. [CrossRef] 
129. Carballo, R.; Sánchez, M.; Ramos, V.; Fraguela, J.; Iglesias, G. The intra-annual variability in the performance of wave energy converters: A comparative study in N Galicia (Spain). Energy 2015, 82, 138-146. [CrossRef]

130. Iglesias, G.; Carballo, R. Wave farm impact: The role of farm-to-coast distance. Renew. Energy 2014, 69, 375-385. [CrossRef]

131. Smith, H.C.; Pearce, C.; Millar, D.L. Further analysis of change in nearshore wave climate due to an offshore wave farm: An enhanced case study for the Wave Hub site. Renew. Energy 2012, 40, 51-64. [CrossRef]

132. Chang, G.; Ruehl, K.; Jones, C.; Roberts, J.; Chartrand, C. Numerical modeling of the effects of wave energy converter characteristics on nearshore wave conditions. Renew. Energy 2016, 89, 636-648. [CrossRef]

133. Millar, D.; Smith, H.; Reeve, D. Modelling analysis of the sensitivity of shoreline change to a wave farm. Ocean Eng. 2007, 34, 884-901. [CrossRef]

134. Bento, A.R.; Rusu, E.; Martinho, P.; Soares, C.G. Assessment of the changes induced by a wave energy farm in the nearshore wave conditions. Comput. Geosci. 2014, 71, 50-61. [CrossRef]

135. Atan, R.; Finnegan, W.; Nash, S.; Goggins, J. The effect of arrays of wave energy converters on the nearshore wave climate. Ocean Eng. 2019, 172, 373-384. [CrossRef]

(C) 2020 by the authors. Licensee MDPI, Basel, Switzerland. This article is an open access article distributed under the terms and conditions of the Creative Commons Attribution (CC BY) license (http://creativecommons.org/licenses/by/4.0/). 